\title{
Retrieval of spectral aerosol optical thickness over land using ocean color sensors MERIS and SeaWiFS
}

\author{
W. von Hoyningen-Huene, J. Yoon, M. Vountas, L. G. Istomina, G. Rohen, T. Dinter, A. A. Kokhanovsky, and \\ J. P. Burrows \\ Institute of Environmental Physics, University of Bremen, Bremen, Germany \\ Received: 24 March 2010 - Published in Atmos. Meas. Tech. Discuss.: 12 May 2010 \\ Revised: 21 December 2010 - Accepted: 22 December 2010 - Published: 3 February 2011
}

\begin{abstract}
For the determination of aerosol optical thickness (AOT) Bremen AErosol Retrieval (BAER) has been developed. Method and main features on the aerosol retrieval are described together with validation and results. The retrieval separates the spectral aerosol reflectance from surface and Rayleigh path reflectance for the shortwave range of the measured spectrum of top-of-atmosphere reflectance for wavelength less than $0.670 \mu \mathrm{m}$. The advantage of MERIS (Medium Resolution Imaging Spectrometer on the Environmental Satellite - ENVISAT - of the European Space Agency - ESA) and SeaWiFS (Sea viewing Wide Field Sensor on OrbView-2 spacecraft) observations is the availability of several spectral channels in the blue and visible range enabling the spectral determination of AOT in 7 (or 6) channels $(0.412-0.670 \mu \mathrm{m})$ and additionally channels in the NIR, which can be used to characterize the surface properties. A dynamical spectral surface reflectance model for different surface types is used to obtain the spectral surface reflectance for this separation. The normalized differential vegetation index (NDVI), taken from the satellite observations, is the model input. Further surface bi-directional reflectance distribution function (BRDF) is considered by the Raman-PintyVerstraete (RPV) model. Spectral AOT is obtained from aerosol reflectance using look-up-tables, obtained from radiative transfer calculations with given aerosol phase functions and single scattering albedos either from aerosol models, given by model package "optical properties of aerosol components" (OPAC) or from experimental campaigns. Validations of the obtained AOT retrieval results with data of Aerosol Robotic Network (AERONET) over Europe gave a preference for experimental phase functions derived from al-
\end{abstract}

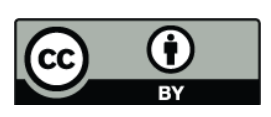

Correspondence to:

W. von Hoyningen-Huene

(hoyning@iup.physik.uni-bremen.de) mucantar measurements. Finally long-term observations of SeaWiFS have been investigated for 11 year trends in AOT. Western European regions have negative trends with decreasing AOT with time. For the investigated Asian region increasing AOT have been found.

\section{Introduction}

Several applications in climate research and environmental control require a determination of spectral aerosol optical thickness. Since most of the aerosol source regions are on land, retrieval methods for applications over land are of importance. Other than over ocean, where the surface reflectance in the NIR is negligible and the retrieval approaches can assume as "black" surface, land surface cannot be assumed as "black" and need to be estimated and corrected. Therefore all land applications for the determination of aerosol need a separation of land surface properties from atmosphere before one can retrieve aerosol optical thickness.

Dual- or multi-view techniques, like in approaches using data of the ATSR-2, AATSR ((Advanced) Along Track Scanning Radiometer) or the MISR (Multiangle Imaging SpectroRadiometer) instruments, can separate the surface properties from two (or even more - for MISR) collocated observations under different viewing angles, assuming that atmosphere and surface can be described sufficiently for both observations.

Ocean colour sensors, like MERIS or SeaWiFS are single view instruments and the spectral surface contribution needs to be estimated from the observed spectral properties of top-of-atmosphere reflectance. Retrieval approaches for such sensors are provided by von Hoyningen-Huene et al. (2003) and Hsu et al. (2004). An overview of the present

Published by Copernicus Publications on behalf of the European Geosciences Union. 

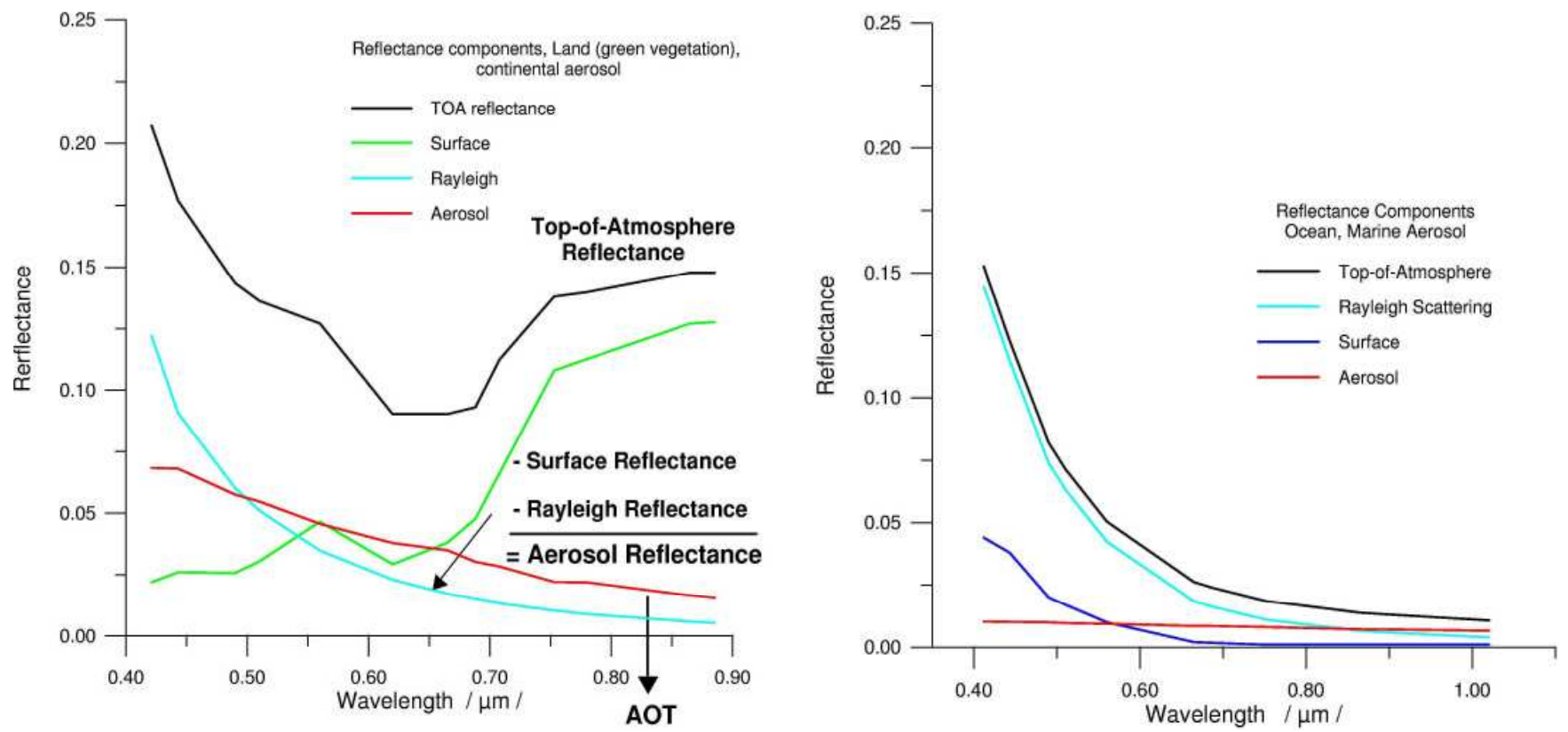

Fig. 1. Main spectral properties of land and ocean surface and its TOA reflectance. Left: land conditions with continental aerosol, right: ocean conditions with clean marine aerosol. Restrictions for the aerosol retrieval over land arise from increase of surface reflectance due to the "red edge" $(\lambda>0.67 \mu \mathrm{m})$ and an increased variability of surface reflectance by the chlorophyll peak at $0.55 \mu \mathrm{m}$.

status of aerosol retrieval from space is given in several contributions to Kokhanovsky and de Leeuw (2009). The aim of this contribution is to describe the aerosol remote sensing approach, called Bremen AErosol Retrieval (BAER), for multi-spectral single-view instruments in its present status. From its first publication (von Hoyningen-Huene et al., 2003) significant improvements of BAER have been made, which will be presented here. The main change compared to older publications is the consideration of a non-Lambertian surface, which reduced the random sacttering of the retrieved AOT results in comparison with ground-based observations as shown in Dinter et al. (2009).

\section{Requirements for ocean colour instruments for aerosol investigations over land}

Since the surface contribution cannot be neglected in aerosol retrievals over land, like over ocean, it needs to be corrected. Therefore a retrieval of aerosol optical thickness (AOT) over land requires sufficient spectral information on top-of-atmosphere (TOA) reflectance in the blue, VIS and NIR channels, to estimate the surface contribution, its spectral properties and to correct them for suitable channels, where the surface contribution is weak. One needs a spectral region, where the surface reflectance is low enough to be corrected and to perform the aerosol retrieval. Furthermore a spectral region is needed, where information on the surface properties, like the vegetation status can be estimated.
Figure 1 illustrates the general different properties of the TOA reflectance and its components over land (left) and ocean (right).

Over ocean the surface reflectance as well the Rayleigh path reflectance is low in the NIR for wavelengths $\lambda>$ $0.67 \mu \mathrm{m}$. Thus aerosol is the dominating influence. Therefore over ocean conditions this region is used for the retrieval of the spectral AOT.

Over land the TOA reflectance in the NIR is dominated by the highly variable strong reflectance of the land surface, as there is the high reflectance of the green vegetation, changing with vegetation type, status and vegetation cover. Generally, land surface reflectance decreases with decreasing wavelength. Since for the aerosol retrieval the surface reflectance in the blue and UV part of the spectrum cannot be neglected, it needs to be estimated in an adequate way. Although Rayleigh path reflectance increases with decreasing wavelength, it can be calculated with sufficient accuracy, because wavelength and air pressure are known.

Thus, instruments for the retrieval of AOT over land require channels in the blue and shortwave visible spectral region for the retrieval of the aerosol and additionally channels in the NIR to estimate the surface properties. The spectral channels of the MERIS (Bezy ez al., 2000) and SeaWiFS instruments are listed in Table 1. In Table 1 the channels used for the aerosol retrieval over land are indicated by AOT(L) and the channels used for the estimation of surface properties by NDVI (Normalized Differential Vegetation Index). Channels, used for AOT retrieval over ocean are indicated by $\operatorname{AOT}(\mathrm{O})$. 
Table 1. Spectral channels of MERIS and SeaWIFS.

\begin{tabular}{ccccl}
\hline MERIS & \multicolumn{3}{c}{ SeaWiFS } & \multicolumn{1}{l}{ Remarks } \\
\hline Channels & 15 & Channels & 8 & \\
\hline Wavelength $(\mu \mathrm{m})$ & Band width $(\mu \mathrm{m})$ & Wavelength $(\mu \mathrm{m})$ & Band width $(\mu \mathrm{m})$ & \\
\hline 0.4127 & 0.00994 & 0.412 & 0.02 & AOT(L) \\
0.4426 & 0.00995 & 0.443 & 0.02 & AOT(L) \\
0.4899 & 0.00996 & 0.490 & 0.02 & AOT(L) \\
0.5098 & 0.00996 & 0.510 & 0.02 & AOT(L) \\
0.5597 & 0.00997 & 0.555 & 0.02 & AOT(L) \\
0.6196 & 0.00998 & & & AOT(L) \\
0.6646 & 0.00999 & 0.670 & 0.02 & AOT(L,O),NDVI \\
0.6808 & 0.00749 & & & \\
0.7083 & 0.00999 & & & AOT(O) \\
0.7534 & 0.00750 & & & O ${ }_{2}$-A absorption \\
0.7615 & 0.00374 & & & AOT(O) \\
0.7784 & 0.01501 & 0.765 & 0.04 & AOT(O)NDVI \\
0.8648 & 0.02004 & 0.865 & & AOT(O) \\
0.8849 & 0.01001 & & & H ${ }_{2}$ O \\
0.9000 & 0.01002 & & & \\
\hline
\end{tabular}

Table 2. Observation characteristics of the instruments.

\begin{tabular}{lllll}
\hline Instrument & $\begin{array}{l}\text { Swath } \\
\text { width }(\mathrm{km})\end{array}$ & $\begin{array}{l}\text { Spatial } \\
\text { resolution }\left(\mathrm{km}^{2}\right)\end{array}$ & Coverage & $\begin{array}{l}\text { Repetition time } \\
(\text { days })\end{array}$ \\
\hline MERIS & & & Global & $2-3$ \\
RR mode & 1100 & $1.1 \times 1.1$ & Europe & \\
FR mode & 1100 & $0.3 \times 0.3$ & Receiving stations & 1 \\
SeaWiFS & & $1.1 \times 1.1$ & Global & $1-2$ \\
LAC mode & 2801 & $4.5 \times 4.5$ & Global & 1 \\
$\begin{array}{l}\text { GAC mode } \\
\text { MODIS }\end{array}$ & 1502 & $1 \times 1$ & & \\
1 km agglom. & 2330 & & & \\
\hline
\end{tabular}

If the requirements of the WMO Global Climate Observing System (GCOS, 2006) should be fulfilled, AOT should be determined with 0.01 . For a resolution of AOT of \pm 0.01 , depending on the aerosol type, the aerosol reflectance should be detected within \pm 0.001 . If all other influences were known, then this is the required accuracy of TOA reflectance. Therefore for the task of aerosol retrieval instruments with large signal-to-noise-ratio - SNR $(\geq 1000)$ should be preferred, like MERIS, SeaWiFS or MODIS. Unless this requirement, the needed assumptions, used by satellite based aerosol retrievals in general will presently not satisfy the GCOS requirement.

The absolute accuracy in TOA reflectance is for MERIS about 3\% (Delwart et al., 2003; Martiny et al., 2005b) and SeaWiFS 4\% (Martiny et al., 2005a). This is sufficient, if one considers that disturbing effects, like land surface and Rayleigh path reflectance, are not accounted for in the above estimation. For the aerosol retrieval over land it is of importance, that the instrument does not reach saturation in its radiometric sensitivity. There is no saturation problem in the cases of MERIS and SeaWiFS. Unfortunately the ocean channels of the Moderate Resolution Imaging Spetroradiometer (MODIS), which have the same wavelengths as SeaWiFS saturate under some land conditions. Thus MODIS land and atmospheric channels have to be used for the AOT retrieval (Kaufman et al., 1997b) with deviating wavelengths from those of MERIS and SeaWiFS BAER variants.

The maximal spatial resolution of MERIS is $0.3 \times 0.3 \mathrm{~km}$ in the full resolution mode (FR). However for the retrieval of AOT mostly the reduced resolution mode (RR) is used with $1.04 \times 1.2 \mathrm{~km}$. This is similar to the local area cover (LAC) of the SeaWiFS instrument with $1.1 \times 1.1 \mathrm{~km}$ or to $1 \times 1 \mathrm{~km}$ 


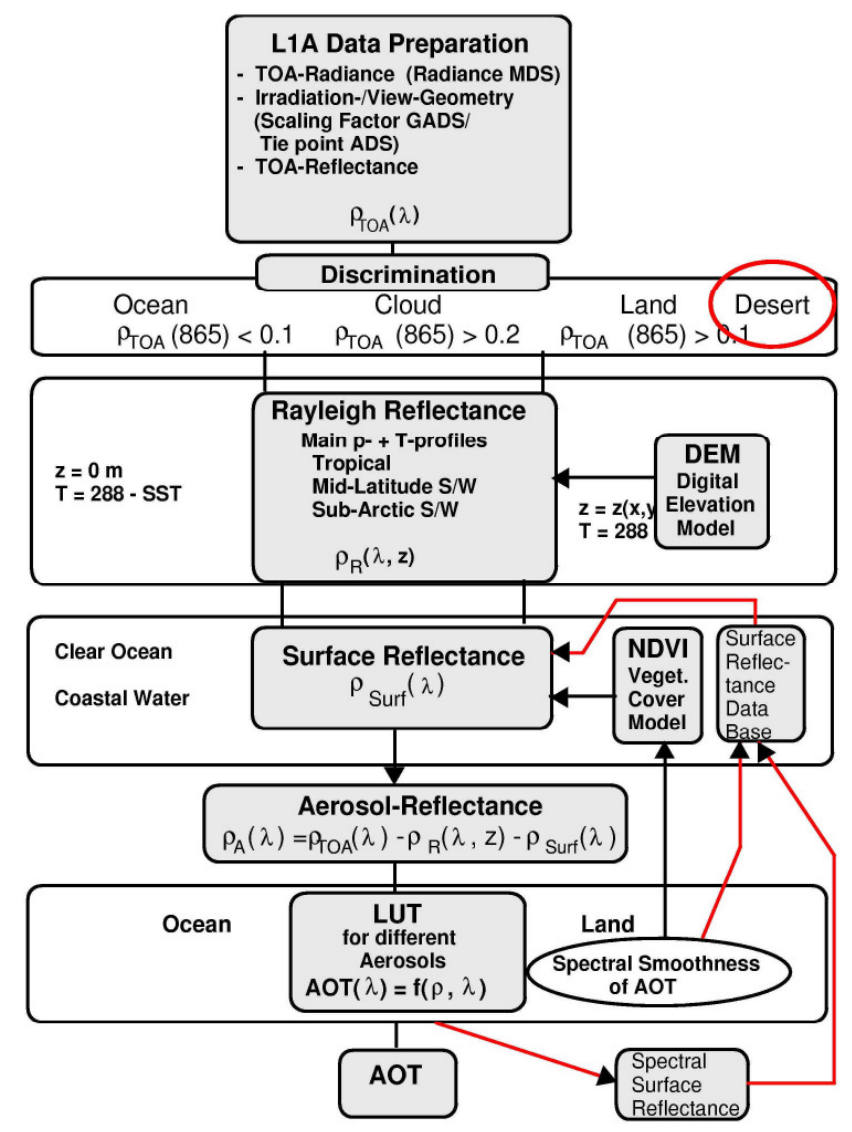

Fig. 2. Scheme of the main steps of BAER and its interactions.

agglomerated data of the MODIS instrument. SeaWiFS data are provided also in global area cover (GAC) with spatial resolution of about $4.5 \times 4.5 \mathrm{~km}$.

A summary and comparison of the instrument parameters, like swath width, spatial resolution, coverage and repetition time are given in Table 2.

The SeaWiFS instrument has the advantage over MERIS and MODIS to operate in a mode 20 deg tilted away from the sun in the direction of the track. This avoids strong sun-glint effects over the ocean. It also reduces the BRDF effects from land surface. Thus, the BRDF model in Sect. 3.3 is not so sensitive to the parameter choice. Since for MERIS no techniques are applied to avoid sun-glint, over ocean about $40 \%$ of the swath is contaminated by sun-glint in lower latitudes.

\section{Bremen AErosol Retrieval (BAER)}

\subsection{Main steps of BAER}

The main steps of BAER described in detail in the following sections are summarized in Fig. 2.

The reading procedure selects the needed measured and auxiliary data for the determination of the required aerosol reflectance. These are solar and viewing geometry, geographical coordinates, TOA radiance, extraterrestrial solar radiation and prepares the TOA reflectance for the retrieval of aerosol reflectance and AOT. Also the surface elevation data for the consideration in the Rayleigh path reflectance calculations are taken from a digital elevation model, GTOPO30 from US Geological Survey (USGS) and are assimilated within the scene.

At first a discrimination step analyses the TOA reflectance $\rho_{\text {TOA }}(0.865 \mu \mathrm{m})$ at the wavelength of $0.865 \mu \mathrm{m}$ and the surface elevation data $z$ to discriminate land, ocean and clouds and directs the scene to the corresponding routines of the program. Land is selected if $z>0 \mathrm{~m}$ and $\rho_{\mathrm{TOA}} \geq 0.1$, ocean is selected with $z=0 \mathrm{~m}$ and $\rho_{\mathrm{TOA}}<0.1$ and clouds are selected by the cloud screening of Sect. 3.6. Additionally the NDVI (Normalized Differential Vegetation Index), Eq. (6) is used to discriminate land from water.

For ocean targets an ocean surface is used instead of the land surface and the ocean algorithm is therefore much more simple than the land part. It can benefit of the low water surface reflectance in the NIR channels of the instruments and use therefore all MERIS or SeaWiFS channels. The principle of the ocean algorithm is the same as for the land algorithm with different surface properties. Thus we do not describe the ocean algorithm separately.

Aerosol reflectance as it is described in Sect. 3.3. is determined for cloud free land and ocean targets, and if it is obtained, AOT according to Sect. 3.4 is retrieved. For this Rayleigh path reflectance is calculated for the given illumination and viewing geometry conditions, the height conditions, using barometric pressure equation and dry adiabatic lapse rate for the consideration of elevation effects for the determination of Rayleigh optical thickness and air mass factors.

After this step the surface reflectance model (Eq. 6) is used for the initialization of the iterative determination of spectral AOT: (a) determination of aerosol reflectance, (b) derivation of AOT by the selected LUT, (c) analysis of the smoothness of spectral AOT by RMSD between retrieved and Angström power law approximation and (d) correction of spectral surface reflectance until RMSD $<0.005$ or return to (a). The iterative procedure to constrain smoothness is described in Sect. 3.5.

If the RMSD has reached 0.005 , then the spectral AOT for all channels below the red edge is obtained. Together with this the Angström spectral slope $\alpha$ for the spectral range of $0.412-0.865 \mu \mathrm{m}$ is found. With this an extrapolation of spectral AOT for all MERIS channels above the red edge is made and an atmospheric correction is performed to calculate spectral surface reflectance for all MERIS channels.

\subsection{The TOA reflectance}

Nadir viewing satellite instruments generally measure the up-welling directed radiance $L^{\uparrow}$, giving the top of atmosphere (TOA) reflectance $\rho_{\mathrm{TOA}}(\lambda)=\frac{\pi L^{\uparrow}(\lambda)}{E_{0}(\lambda) \cdot \cos \left(z_{0}\right)}$, by 
reference to its solar irradiation $E_{0}$, for the zenith distance $z_{0}$ for each considered wavelength $\lambda$. The spectral dependence of all radiative properties is omitted in the following equations. Following Kaufman et al. (1997a), the topof-atmosphere reflectance (Eq. 1) is composed of the atmospheric path reflectance $\rho_{\text {Atmos }}^{\text {Black }}$ and the surface contribution, influenced by the atmosphere (second term). There $\rho_{\text {Atmos }}^{\text {Black }}$ is the atmospheric path reflectance for a "black" underlying surface. It depends on $\delta_{\text {Aer, }}, \delta_{\text {Ray }}-$ the optical thickness for aerosol and Rayleigh scattering, $p(\theta)$ is the atmospheric phase function, composed of aerosol and Rayleigh scattering, depending on scattering angle $\theta, \omega_{0}$ - the single scattering albedo of atmosphere and the geometry conditions, the zenith distances for illumination $z_{0}$ and viewing $z_{S}$ and the relative azimuth $\phi$. The second term is determined by the surface albedo $A_{\text {Surf }}$, the total transmission $t_{\text {tot }}$ for the illumination and viewing geometry and the hemispheric reflectance $r_{\mathrm{Hem}}$.

$$
\begin{aligned}
\rho_{\mathrm{TOA}}\left(z_{0}, z_{S}, \phi\right)= & \rho_{\mathrm{Atmos}}^{\text {Black }}\left(z_{0}, z_{S}, \phi, \delta_{\mathrm{Aer}}, \delta_{\mathrm{Ray}}, p(\theta), \omega_{0}, 0\right) \\
& +\frac{t_{\mathrm{tot}}\left(z_{0}\right) t_{\mathrm{tot}}\left(z_{S}\right) A_{\mathrm{Surf}}\left(z_{0}, z_{S}\right)}{1-A_{\mathrm{Surf}}\left(z_{0}, z_{S}\right) r_{\mathrm{Hem}}\left(\delta_{\mathrm{tot}}, g\right)}
\end{aligned}
$$

Equation (1) is valid for each wavelength, e.g. all parameters have to be known with their spectral properties for the channels used.

This equation is in a good agreement with reality, if ocean conditions in the red and NIR are known.

However, over land with a real surface reflectance, which is not "black", multiple scattering between surface and atmosphere introduces coupling terms between all components of the radiation transfer, causing deviations from idealized assumptions. Further the combined atmospheric path reflectance disables a simple separation of the aerosol path reflectance for a retrieval of aerosol optical thickness from the combination with the Rayleigh scattering and multiple scattering effects.

\subsection{Aerosol reflectance over land}

The basic approach of the Bremen AErosol Retrieval (BAER) is described in von Hoyningen-Huene et al. (2003, 2006).

For the retrieval of aerosol optical thickness, the separation of aerosol reflectance from top-of-atmosphere reflectance is required by correcting for the Rayleigh path reflectance $\rho_{\text {Ray }}$ and the surface term.

$$
\begin{gathered}
\rho_{\text {Aer }}\left(z_{0}, z_{S}, \phi, \delta_{\text {Aer }}, p_{\text {Aer }}(\theta), \omega_{0}, 0\right)=\rho_{\mathrm{TOA}}\left(z_{0}, z_{S}, \phi\right) \\
-\rho_{\text {Ray }}\left(z_{0}, z_{S}, \phi, \delta_{\text {Ray }}, p, 0\right) \\
-\frac{t_{\text {tot }}\left(z_{0}\right) t_{\text {tot }}\left(z_{S}\right) A_{\text {Surf }}}{1-A_{\text {Surf }} r_{\text {hem }}\left(\delta_{\text {tot }}, g\right)}
\end{gathered}
$$

In this form $\rho_{\text {Aer }}$ contains aerosol reflectance and multiple scattering effects between molecules, which can be

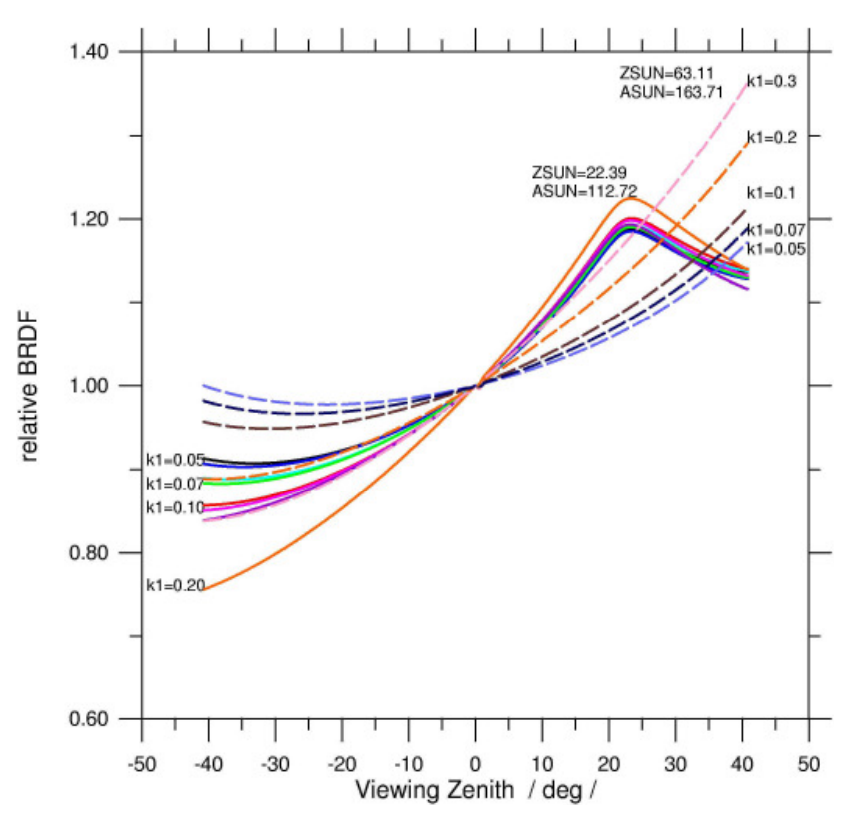

Fig. 3. Relative BRDF calculated for two illumination conditions (solar zenith angles $22.39^{\circ}$ and $63.11^{\circ}$ ) and the viewing range of MERIS for different parameters of the RPV model, used in the VIS channels.

considered within the look-up-tables. Rayleigh path reflectance $\rho_{\text {Ray }}$ is calculated by a radiative transfer model, using Rayleigh optical thickness for a given wavelength (Buchholz, 1995), the Rayleigh phase function, the illumination and viewing geometry and the actual temperature and pressure conditions at the surface. Barometric height equation and dry adiabatic lapse rate are used together with the digital elevation model (GTOPO30) to correct Rayleigh path reflectance and air mass factors to the actual conditions within the satellite scene, $\delta_{\text {Ray }}(\lambda, p, T)=\frac{p}{p_{0}} \cdot \frac{T_{0}}{T} \cdot \delta_{\text {Ray }}(\lambda)$. Sea level pressure $p_{0}$ is taken from ECMWF data or if not available as standard pressure, $T_{0}$ is obtained from a climatology of Max-Planck-Institute in Hamburg.

The correction of the surface effects requires the application of a surface model, which can be adapted to the spectral and geometry conditions of the satellite scene. The consideration of the surface term requires the knowledge of the spectral surface albedo $A_{\text {Surf }}$, if the surface can be assumed as Lambertian. Investigations of Dinter et al. (2009) showed significant bias in the AOT depending on swath position, if Lambertian surface assumption is used. Since the land surface is in reality a non-Lambertian ground, the spectral surface albedo has to be substituted by the directed spectral surface reflectance:

$\rho_{\text {Surf }}\left(\lambda, z_{0}, z_{S}, \phi\right)=\operatorname{BRDF}\left(z_{0}, z_{S}, \phi\right) \cdot A(\lambda)$

$\operatorname{BRDF}\left(z_{0}, z_{S}, \phi\right)$ is the normalized bi-directional reflection function to the nadir position, based on the Raman-PintyVerstraete model (RPV) (Maignan et al., 2004) describing 


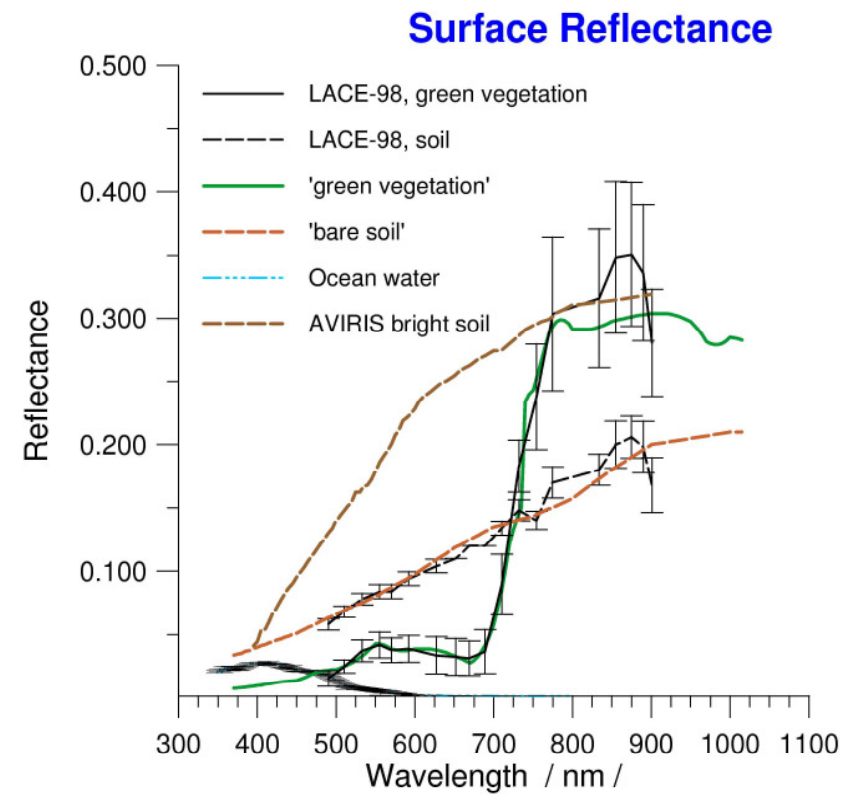

Fig. 4. Main surface reflectance spectra used for the surface reflectance model such as "green vegetation" and "bare soil" in comparison with experimental data. The high reflectance of bright soil causes additional restrictions for the aerosol retrieval.

the relative deviation of the reflectance for the given illumination and viewing conditions. Examples are presented in Fig. 3. The relative BRDF shows a significant deviation from Lambertian conditions $\left(\operatorname{BRDF}\left(z_{0}, z_{S}, \phi\right)=\right.$ const $\left.=1.0\right)$. The shape of the BRDF can be described by 3 parameters. Since the parameters depend on surface type, the selection of the appropriate shape parameters is still an open task. The analysis of POLDER observations can help to establish a regional data base of the required parameters. Ignoring BRDF leads to a bias of AOT along the viewing geometry or requires the application of apparent aerosol phase functions, including BRDF effects.

The present realization of BAER uses one set of BRDF parameters for the whole scene, ignoring regional variations. The BRDF parameters to be used are still under investigation, because they are variable and depending on the surface type. The normalized BRDF is used as

$\operatorname{BRDF}\left(z_{0}, z_{S}, \phi, \lambda\right)=\frac{\operatorname{BRDF}^{*}\left(z_{0}, z_{S}, \phi, \lambda\right)}{\operatorname{BRDF}^{*}\left(z_{0}, z_{S}=0, \phi, \lambda\right)}$,

where BRDF* is described by the RPV model.

$$
\begin{aligned}
\operatorname{BRDF}^{*}\left(z_{0}, z_{S}, \phi, \lambda\right)= & \rho_{\text {Surf }}(\lambda) \cdot \frac{\cos ^{k-1} z_{0} \cdot \cos ^{k-1} z_{S}}{\left(\cos z_{0}+\cos z_{S}\right)^{1-k}} \\
& \cdot \frac{1-\varphi^{2}}{\left(1+\varphi^{2}-2 \varphi \cos (\pi-\arccos \theta)\right)^{1.5}} \\
& \cdot\left(1+\frac{1-\rho_{\text {Surf }}(\lambda)}{1+G}\right)
\end{aligned}
$$

with $G=\sqrt{\tan ^{2} z_{0}+\tan ^{2} z_{S}-2 \cdot \tan z_{0} \cdot \tan z_{S} \cdot \cos \phi}$.
The input parameters are $\rho_{\text {Surf }}(\lambda)$, taken from a first guess with Eq. (6), made for Lambertian conditions $(\mathrm{BRDF}=1), k$ and $\varphi$ as model parameters and the geometry conditions with $\theta$ as scattering angle and the solar and viewing zenith angles. $k$ describes the surface anisotropy and $\varphi-$ the forward backward scattering of the surface. Thus the diffuse directed reflection of the surface can be described. As preliminary values, $k=0.65$ and $\varphi=-0.06$ are used, obtained from sites over Germany, minimizing the AOT deviations from ground based AERONET data. With these settings the bias along the viewing geometry of the Lambertian ground could be reduced for MERIS observations. However, not all regional variations disappear and a regional variable data set is required. For SeaWiFS data the sensor tilt reduces the BRDF effect, thus the values found over Germany seem to be sufficient.

The spectral properties and the magnitude of the surface are given by the spectral albedo, described by a linear mixing model, using two basic spectra for "green vegetation" $\rho_{\mathrm{Veg}}(\lambda)$ and "bare soil" $\rho_{\text {Soil }}(\lambda)$. Since the spectral properties of the surface reflectance will be expressed by $\rho_{\text {Surf }}^{\diamond}(\lambda)=$ $C_{\mathrm{Veg}} \cdot \rho_{\mathrm{Veg}}(\lambda)+\left(1-C_{\mathrm{Veg}}\right) \cdot \rho_{\text {Soil }}(\lambda)$, the surface albedo will be

$$
\begin{aligned}
A_{\mathrm{Surf}}\left(\lambda, z_{0}, z_{S}, \phi\right)= & \frac{\mathrm{SF}}{\operatorname{BRDF}\left(z_{0}, z_{S}, \phi\right)} \cdot \rho_{\mathrm{Surf}}^{\diamond} \\
= & \frac{\mathrm{SF}}{\operatorname{BRDF}\left(z_{0}, z_{S}, \phi\right)} \\
& \cdot\left(C_{\mathrm{Veg}} \cdot \rho_{\mathrm{Veg}}(\lambda)+\left(1-C_{\mathrm{Veg}}\right) \cdot \rho_{\mathrm{Soil}}(\lambda)\right) .
\end{aligned}
$$

As proxy for the vegetation fraction the NDVI is used.

$C_{\text {Veg }}=\mathrm{NDVI}^{*}=\frac{\rho^{*}(0.865 \mu \mathrm{m})-\rho^{*}(0.665 \mu \mathrm{m})}{\rho^{*}(0.865 \mu \mathrm{m})+\rho^{*}(0.665 \mu \mathrm{m})}$

with $\rho^{*}=\rho_{\mathrm{TOA}}-\rho_{\text {Ray }}-\rho_{\text {Aer }}^{\text {Guess }}$ is taken from the $\mathrm{NDVI}^{*}$, the atmospherically corrected NDVI of the scene, and the scaling factor SF is used to adapt the spectrum to the radiation conditions in the scene

$$
\mathrm{SF}=\frac{\rho_{\mathrm{TOA}}(0.665 \mu \mathrm{m})-\rho_{\text {Ray }}(0.665 \mu \mathrm{m})-\rho_{\mathrm{Aer}}^{*}(0.665 \mu \mathrm{m})}{C_{\mathrm{Veg}} \cdot \rho_{\mathrm{Veg}}(0.665 \mu \mathrm{m})+\left(1-C_{\mathrm{Veg}}\right) \cdot \rho_{\mathrm{Soil}}(0.665 \mu \mathrm{m})}
$$

Since $\rho^{*}$ requires a first guess of the aerosol reflectance, an estimate from channel $1(0.412 \mu \mathrm{m})$ is used, assuming a "black" surface. This gives a first overestimated guess of AOT, since surface reflectance decreases with decreasing wavelength. This AOT is transferred to the channel $0.665 \mu \mathrm{m}$, using Angström power law with an exponent of 1 and giving the estimate of the aerosol reflectance for this channel.

The surface model of Eq. (6) is used in Eq. (2) for the determination of the aerosol reflectance from satellite data. The spectra of both surface types ("green vegetation" and "bare soil") are shown in Fig. 4. Averages of measured data of the LACE-98 experiment (Ansmann et al., 2002; von Hoyningen-Huene et al., 2003) have been combined 


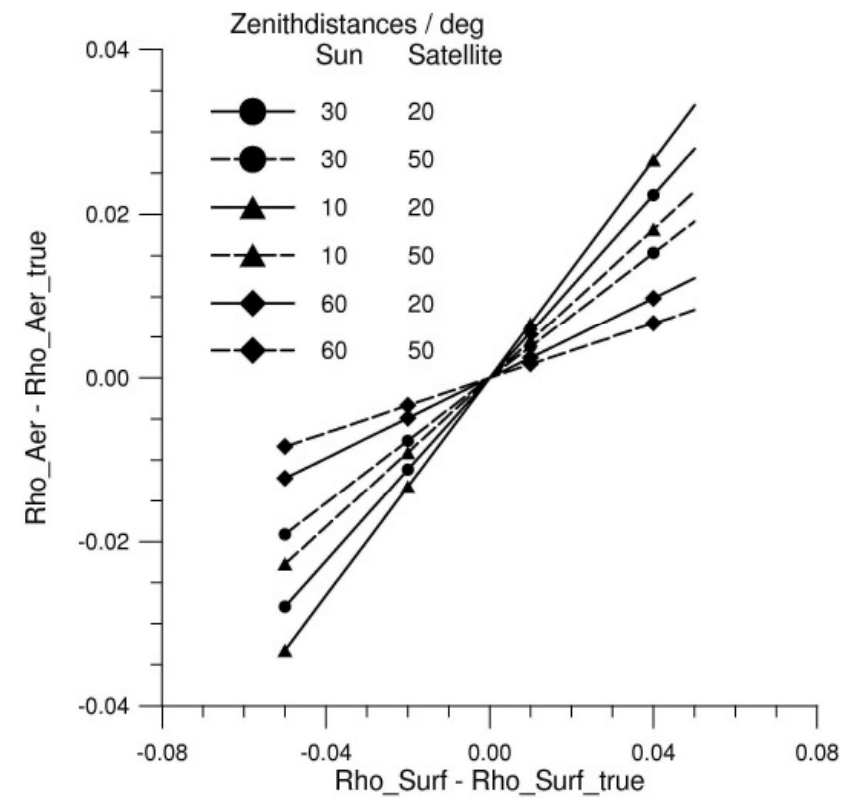

Fig. 5. Sensitivity of aerosol reflectance $\rho_{\text {Aer }}(\lambda)$ against deviations of surface reflectance $\rho_{\text {Surf }}(\lambda)$ from true value for selected geometry conditions.

with measurement of the AVIRIS instrument (Airborne Visible/Infrared Imaging Spectrometer of NASA) to cover the whole spectral range. Figure 4 also indicates the high variability of soil. Bright soil decreases the sensitivity to aerosol, thus the retrieval is more restricted or even impossible.

Over ocean and in the NIR the Fresnel reflectance of the surface is sufficient to be considered, as one can see in Fig. 4. However, for the SW channels water leaving and ocean surface reflectance is required. For SeaWiFS - because of the sensor tilt away from sun - a calculation of the ocean surface reflectance, using Cox and Munk (1954) with the actual geometry conditions of the scenes, is used and is sufficient to correct glint effects. For MERIS this is not sufficient, there glint regions need to be excluded.

The correct estimation of the surface term by the spectral surface model is very important, because it determines directly the accuracy of AOT. A deviation of surface reflectance of 0.01 leads to a change in AOT depending on aerosol type of about 0.1 .

The sensitivity of the aerosol reflectance with respect to deviations of the surface reflectance is shown in Fig. 5. In case of the determination of surface reflectance by the model, Eq. (6) and the iteration described later in Sect. 3.5 we derive the apparent effective surface reflectance of the scene. The aerosol reflectance can be obtained with an accuracy of 0.005 and then the AOT depends on the selected look-up-tables (LUT). The adaptation of the apparent surface reflectance to that situation within the pixel and the minimization of the deviation between the estimation and the real situation is made by three parameters: (a) the scaling factor SF (Eq. 8), adapting the general level of the surface reflectance to radiance level within the scene, (b) the atmospheric corrected NDVI, giving the spectral behaviour of the surface reflectance for the short wave channels and (c) iterative smoothing of the AOT output, making a fine tuning with Eq. (15), described later in Sect. 3.5. Thus, the deviations of the apparent surface reflectance from the true one should come close to zero. Additionally, the aerosol retrieval is made over areas fully or partly covered by vegetation. There, the expected reflectance for the channels $1-7$ is in the range of 0.05 and less. Thus, good conditions for the aerosol retrieval exist.

\subsection{AOT determination}

For the conversion of the reflectance data into AOT look-uptables (LUT) either between top-of-atmosphere reflectance and AOT or aerosol reflectance and AOT are required. For the generation of LUT radiative transfer model calculations have to be performed, using aerosol and surface characteristics, Rayleigh scattering and geometry of illumination and observation. Aerosol characteristics are given by an aerosol phase function, the spectral single scattering albedo and a range of AOT, for instance 0.03-2.5. Since the observation data are corrected to an aerosol reflectance, also the radiative transfer calculations, giving $\rho_{\mathrm{TOA}}^{\mathrm{RTM}}$, are corrected in the same way:

$$
\begin{aligned}
\rho_{\text {Aer }}(\lambda)=\rho_{\mathrm{TOA}}^{\mathrm{RTM}}(\lambda)-\rho_{\mathrm{Ray}}(\lambda) & \\
& -\frac{t_{\mathrm{tot}}\left(z_{0}\right) \cdot t_{\mathrm{tot}}\left(z_{S}\right) \cdot A_{\mathrm{Surf}}(\lambda)}{1-A_{\mathrm{Surf}}(\lambda) \cdot r_{\mathrm{hem}}\left(\delta_{\mathrm{tot}}, g\right)} .
\end{aligned}
$$

Since in this case $\rho_{\text {Ray }}(\lambda)$ and $\rho_{\text {Surf }}(\lambda)$ are known, $\rho_{\text {Aer }}(\lambda)$ starts at 0.0 for AOT $=0$ and contains multiple scattering exchange between aerosols and air molecules. Thus the LUTs contain AOT as functions of aerosol reflectance.

$\delta_{\text {Aer }}(\lambda)=f\left(\rho_{\text {Aer }}\left(\lambda, z_{0}, z_{S}, \phi\right)\right)$

For each geometry constellation and spectral channel one obtains functions, which can be parameterised as polynomials of the second degree:

$$
\begin{aligned}
\delta_{\text {Aer }}(\lambda)= & c_{0}\left(\lambda, z_{0}, z_{S}\right)+c_{1}\left(\lambda, z_{0}, z_{S}\right) \cdot \rho_{\text {Aer }}\left(\lambda, z_{0}, z_{S}\right) \\
& +c_{2}\left(\lambda, z_{0}, z_{S}\right) \cdot \rho_{\text {Aer }}^{2}\left(\lambda, z_{0}, z_{S}\right),
\end{aligned}
$$

resulting in sets of $c_{0}, c_{1}$ and $c_{2}$ coefficients for each geometry constellation and spectral channel. The polynomial fit enables a fast interpolation between the discrete values of the radiative transfer modeling. Thus, for each channel the AOT $\delta_{\text {Aer }}$ is retrieved.

Since this is a quite large number of cases a reduction of cases is made, using air mass corrected aerosol reflectance $\left(\rho_{\text {Aer_AC }}\right)$. For these corrections single scattering in the atmosphere is assumed.

$\rho_{\text {Aer_AC }}=\rho_{\text {Aer }} \cdot \frac{M\left(z_{0}\right)+M\left(z_{S}\right)}{M\left(z_{0}\right) \cdot M\left(z_{S}\right)}$ 

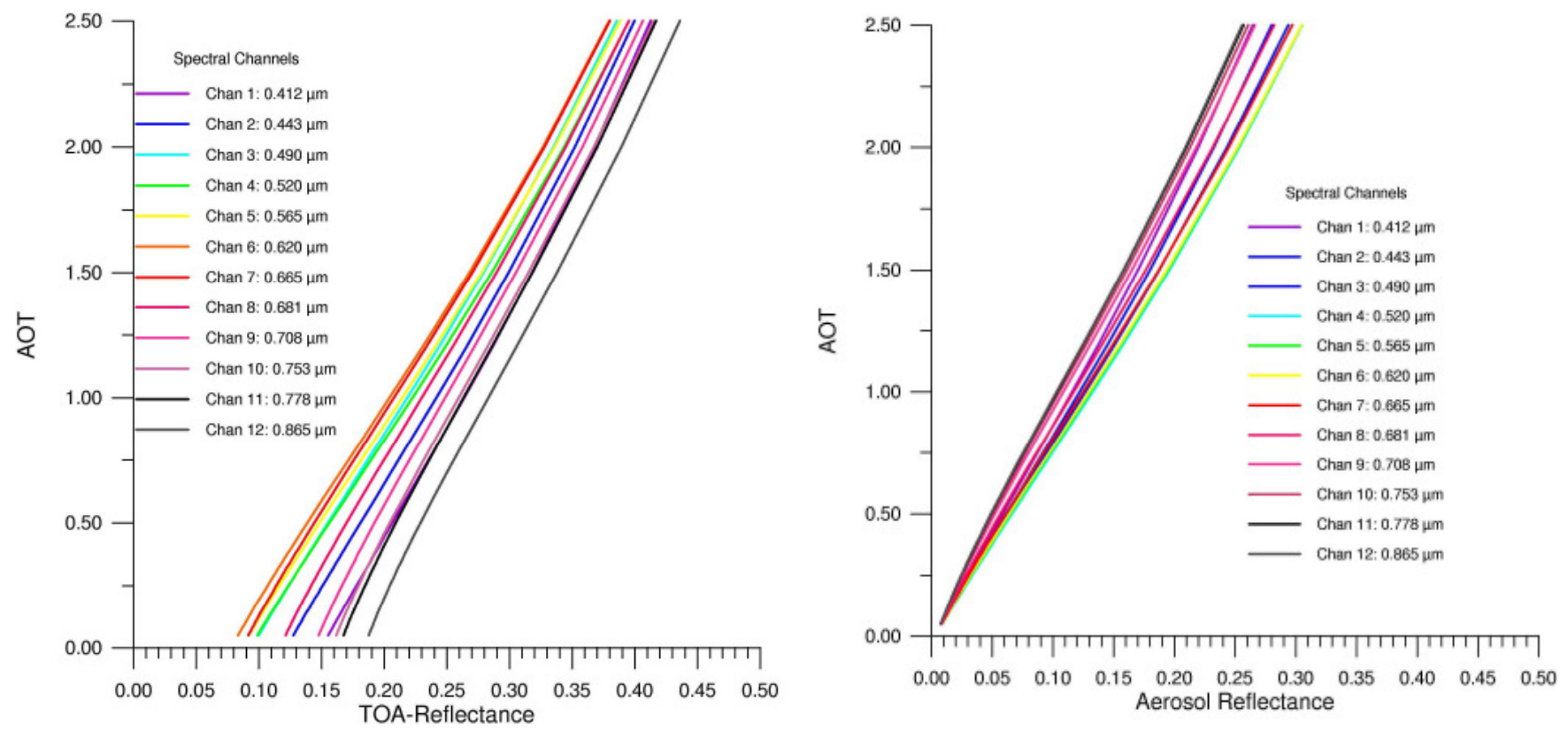

Fig. 6. Examples of spectral look-up-tables to convert (a) left: TOA reflectance to AOT and (b) right: aerosol reflectance into AOT for the main MERIS channels for one given illumination - viewing configuration $\left(z_{0}=38^{\circ}, z_{S}=23^{\circ}, \phi=68^{\circ}\right)$. The example shows results for LUT No. 6 - experimental phase function of LACE-98 and non absorbing aerosol.
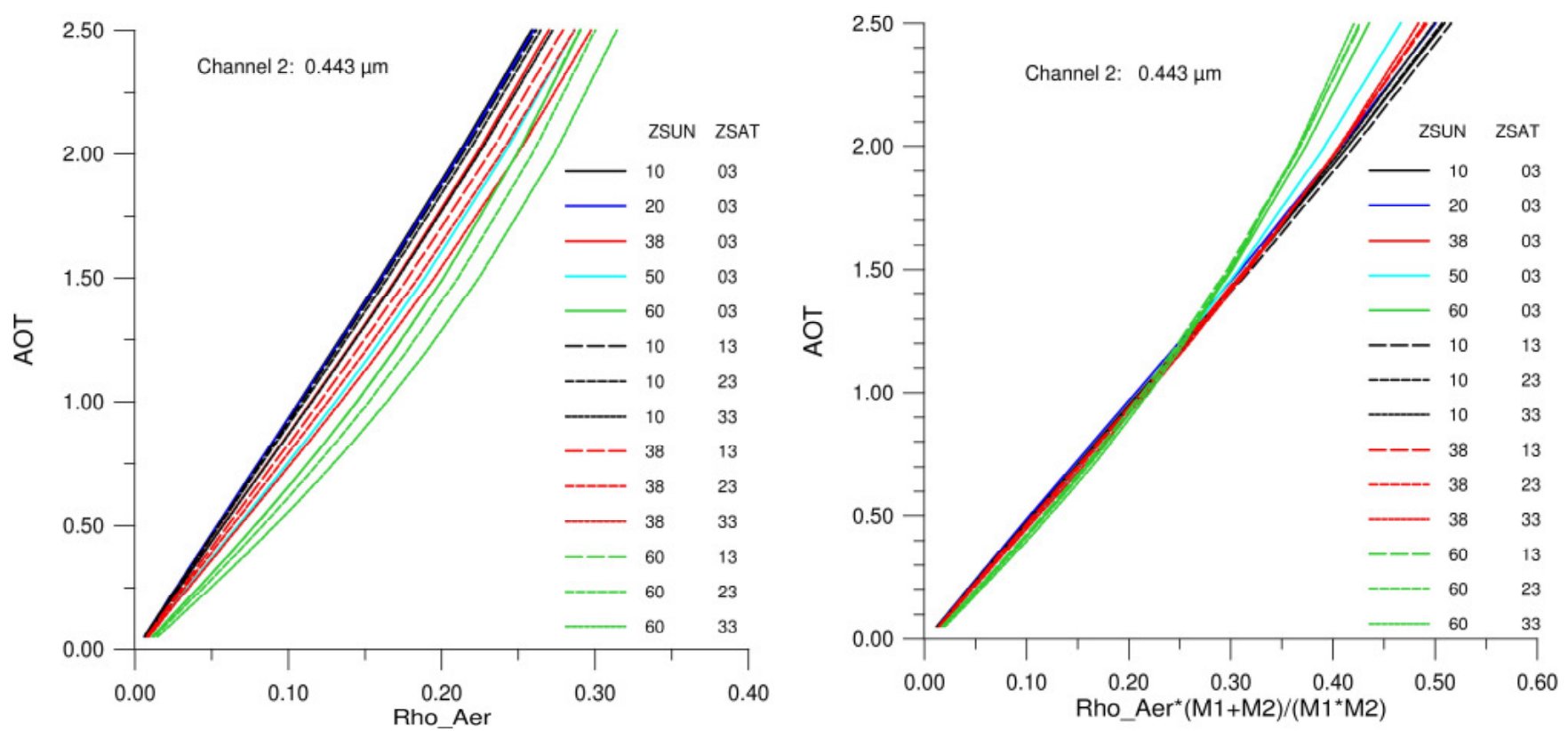

Fig. 7. Dependence of AOT on aerosol reflectance for MERIS channel $2(0.443 \mu \mathrm{m})$. Influence of illumination and viewing geometry on LUT (left) and after its airmass correction (right). The parameter of $\mathrm{x}$-axis of right figure is the air mass - corrected aerosol reflectance given by equation (12)

These air mass - corrected LUTs reduce the number of required relationships to few ones for reference air mass conditions, which also are parameterized in form of polynomials of second degree for a fast processing. As one can see from Fig. 7 this simplification gives quite good approximation for
AOT $<1$. For AOT $>1$ the deviations due to multiple scattering require the correct consideration of the geometry conditions. However, the most situations fulfil the first condition.

Figure 6 gives a graphical example of the LUT content by plotting AOT as function of the aerosol- or TOA 


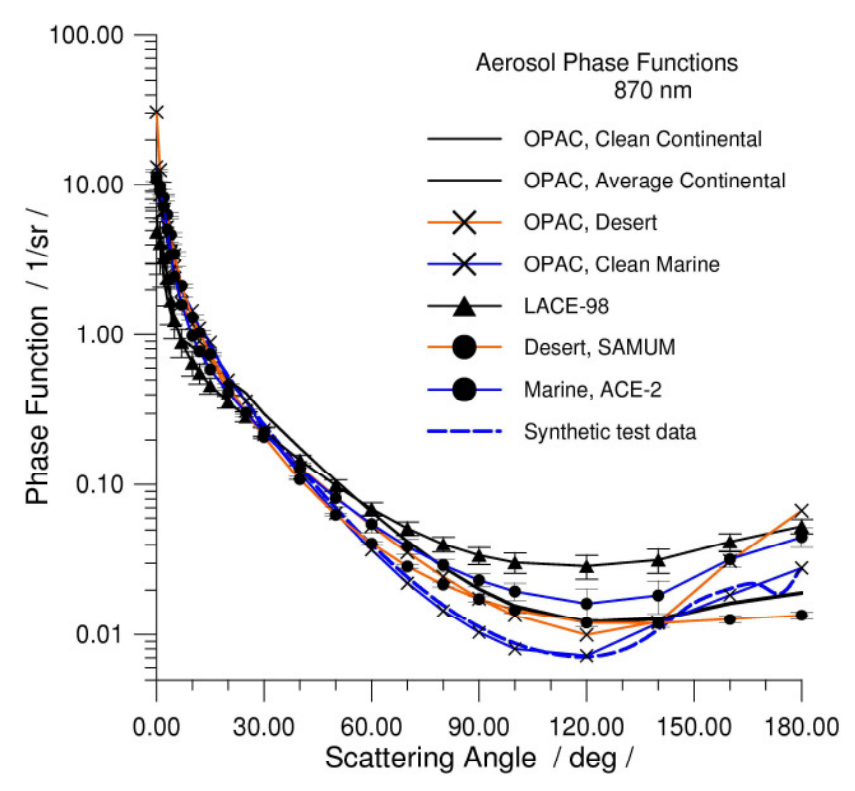

Fig. 8. Experimental phase functions of the experiments, ACE-2, LACE-98 and SAMUM in comparison with phase functions of the OPAC aerosol models, which are used for the LUT calculation. Additionally the dashed line gives the phase function for the synthetic data of the algorithm inter-comparison by Kokhanovsky et al. (2010).

reflectance, computed using "green vegetation" as surface, for non absorbing aerosol and for an experimental aerosol phase function, determined during the LACE-98 experiment, von Hoyningen-Huene, 2003. Figure 7 presents the geometry influence in aerosol reflectance and in the air mass - corrected aerosol reflectance according Eq. 12.

The aerosol characteristics of the radiative transfer calculations for the LUT are the phase function, spectral single scattering albedo and a given range of AOT (like here, 0 2.5). The phase function and single scattering albedo are obtained either from predefined aerosol models, like OPAC (Hess et al., 1998) or from experimental data of sun-/sky radiometer measurements of AERONET (Dubovik and King, 2000; Dubovik, 2002, 2006) or special campaigns, like ACE2, LACE-98, SAMUM (von Hoyningen-Huene et al., 1997, 1999a, b, 2003, 2009; Silva et al., 2002; Ansmann et al., 2002). Aerosol phase functions and single scattering albedo, applied in radiative transfer calculations for LUT are presented in Figs. 8 and 9.

The main characteristics of the aerosol for the LUT are the phase functions. They are normalized to 1 (in $1 / \mathrm{sr}$ ). The spectral change in phase function is neglected within the wavelength range of $0.412-0.670 \mu \mathrm{m}$ for the land retrievals, because experimentally no significant deviations could be found. Also the spectral change in single scattering albedo is neglected, because it is small in the used spectral range. The set of selectable LUTs of BAER is presented in Table 3.

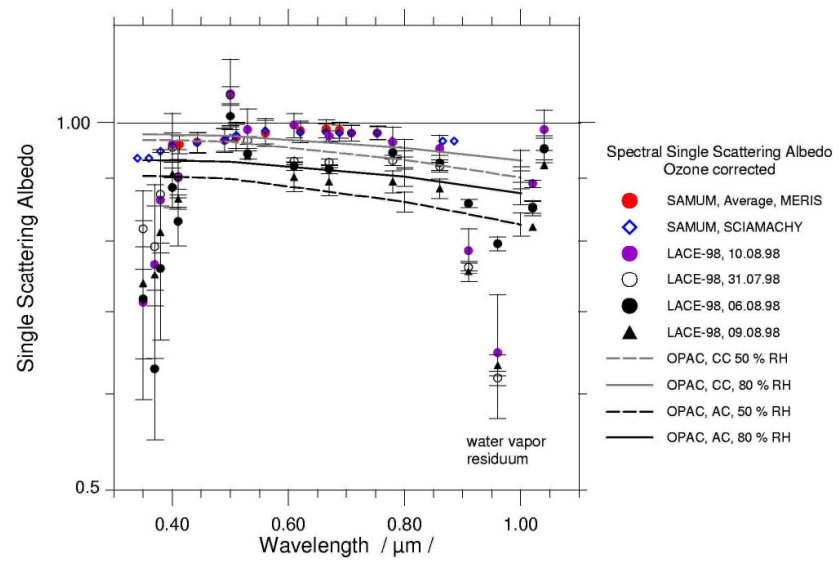

Fig. 9. Experimental spectra of single scattering albedo of LACE98 and SAMUM in comparison with the continental aerosol model of OPAC (AC - average continental, CC - clean continental).

The application of the algorithm with several test scenes, using different LUTs and the validation lead to the conclusion, that LUT No. 6, LACE-98, non-absorbing aerosol worked as an all round LUT, giving close results with AERONET data for the most conditions.

In cases of strong pollution high AOT tends to be underestimated up to $20 \%$ with this LUT. Therefore LUTs with more absorbing aerosol need to be selected.

Applying LUT with the first guess of aerosol reflectance, obtained by the corrections of Rayleigh path reflectance and surface reflectance as described in Sect. 3.3, gives an AOT with a noisy spectral behaviour, varying around the real spectral slope. The spectral AOT obtained has no smooth decreasing spectral behaviour as it should be according to aerosol models. It has over land a noisy disturbed spectral slope, which disables a clear determination of an aerosol type from the 7 channels of the MERIS observation. Therefore an iterative smoothing of the spectral behaviour of the AOT with an application of convergence criteria is required.

\subsection{Constraints, iterative smoothing and convergence criteria for AOT}

Since in the reality the aerosol optical thickness has a smooth spectral behaviour, the noisy disturbed spectral slope, obtained by the application of Eqs. (2) and (10), is constrained to follow approximately an Angström power law

$\overline{\delta_{\text {Aer }}}(\lambda)=\beta \cdot \lambda^{-\alpha}=\delta_{\text {Aer }}\left(\lambda_{\text {ref }}\right) \cdot\left(\frac{\lambda}{\lambda_{\text {ref }}}\right)^{-\alpha}$.

One could use also another spectral aerosol model. However, the information content of the satellite data is not sufficient to separate more sophisticated aerosol models from surface effects without interferences of surface effects. Therefore we selected this simple spectral model for smoothing. 
Table 3. Look-up-tables in use and their characteristics.

\begin{tabular}{cllc}
\hline $\begin{array}{c}\text { LUT } \\
\text { number }\end{array}$ & Aerosol model & Phase function & $\begin{array}{c}\text { Single scattering albedo } \\
(\lambda=0.5 \mu \mathrm{m})\end{array}$ \\
\hline 1 & Clean marine & OPAC, clean marine & 1.0 \\
2 & Clean continental & OPAC, clean continental & 0.975 \\
3 & Average continental & OPAC, average continental & 0.928 \\
4 & ACE-2, marine & ACE-2, experimental & 1.0 \\
5 & LACE-98, absorbing & LACE-98, experimental & 0.98 \\
6 & LACE-98, non-abs. & LACE-98, experimental & 1.0 \\
7 & Desert & SAMUM, experimental & 0.97 \\
\hline
\end{tabular}

The deviations determined from the individual estimates $\delta_{\text {Aer }}\left(\lambda_{l}\right)$ of channel $i$ and the value $\overline{\delta_{\text {Aer }}}\left(\lambda_{i}\right)$ represented by the Angström power law should be minimized, expressed by the

$$
\mathrm{RMSD}=\frac{1}{N} \sqrt{\sum_{i=1}^{N}\left(\delta_{\mathrm{Aer}}\left(\lambda_{i}\right)-\overline{\delta_{\mathrm{Aer}}}\left(\lambda_{i}\right)\right)^{2}}
$$

by modifying the surface reflectance in an iterative scheme running over $j$,

$$
\begin{aligned}
\rho_{\text {Surf }, j}(\lambda)= & \rho_{\text {Surf }, j-1}(\lambda) \cdot w(\lambda) \\
& \cdot\left(1-\frac{\delta_{\text {Aer }, j}(\lambda)-\overline{\delta_{\text {Aer }, j}}(\lambda)}{\delta_{\text {Aer }, j}(\lambda)}\right) .
\end{aligned}
$$

until root mean square deviation, RMSD $<0.005$ is reached.

Here $\beta=\delta_{A}(\lambda=1.0 \mu \mathrm{m})$ is the turbidity coefficient and $\alpha$ is the spectral slope of Angström power law. Instead of $\beta$ another reference wavelength $\lambda_{\text {ref }}$ for the reference AOT can be used, which is in this case the AOT of the first instrument channel with $\lambda_{1}$. This is due to the lowest surface reflectance and therefore the lowest retrieval error by the surface influence. The weighting factors $w(\lambda)$ determine the degree of variation of the surface reflectance spectrum by the iterations and determine the speed of the convergence. Small values are used for reflectance values close to the expected ones and large values for channels with expected larger deviations.

The Angström parameters $\alpha$ and $\beta$ are calculated here by the least squares fit of the Angström power law with the retrievals for all used spectral channels, i.e. channels 1 to 7 over land, instead of the mostly applied two-channel-approaches, cf. Eck et al. (1999).

With this fit, we get:

$\alpha=\frac{\sum_{i=1}^{N}\left[\left(\ln \delta_{\text {Aer }}\left(\lambda_{i}\right)-\overline{\ln \delta_{\text {Aer }}}\right) \cdot\left(\ln \lambda_{i}-\overline{\ln \lambda}\right)\right]}{\left.\sum_{i=1}^{N}\left[\ln \lambda_{i}-\overline{\ln \lambda}\right]^{2}\right)}$

and

$\beta=\exp \left(\overline{\ln \delta_{\text {Aer }}}+\overline{\ln \lambda} \cdot \alpha\right)$

with $N$ - the number of spectral channels used. $\overline{\ln \delta_{\text {Aer }}}=\frac{1}{N} \sum_{i=1}^{N} \ln \delta_{\text {Aer }}\left(\lambda_{i}\right)$ and $\overline{\ln \lambda}=\frac{1}{N} \sum_{i=1}^{N} \ln \lambda_{i}$ describe the averaged logarithms of the spectral AOT and wavelengths, respectively.

This approach gives a much more stable estimation of the Angström parameters for a multi-wavelength approach then a two-wavelength estimation, especially, if one has errors in the first iterations for the AOT of the single channels. Furthermore it is easy to transfer the reference wavelength for the AOT from $\beta=\delta_{\text {Aer }}(1.0 \mu \mathrm{m})$ to each wavelength desired, using Eq. (13). The main purpose of the use of the Angström power law is to ensure a sufficient smoothness of the AOT spectrum.

For the first iteration of the determination of the AOT, the surface reflectance obtained by Eq. (6) is used. Then, the iterative smoothing described in Eq. (15) modifies the spectral surface reflectance depending on deviations of the smoothed spectral AOT. With the modified surface reflectance an improved AOT is obtained and so on, until RMSD has reached its defined minimum. Finally the AOT for the used spectral channels is found and the iteration can be stopped.

Within the iterations the Angström parameters are constrained as follows: The spectral slope $\alpha$ is determined in the first iteration from the retrieved value of the AOT. It is defined to lay within the limits $-0.5 \leq \alpha \leq 2.0$. These boundaries are selected from extreme spectral conditions for the AOT, found in ground-based measurements. If the retrieved spectral slope is outside this limit it is set to the climatologic average of $\alpha=1.3$. This constraint corresponds to the range of the alpha obtained for the majority of atmospheric aerosol types from sunphotometer measurements (Holben et al., 2001) and models cf. d'Almeida et al. (1991).

Extensive applications of the procedure indicate a different impact of the different spectral channels on the determination of spectral slope of AOT. Since the MERIS channels 1 to 4 $(0.412-0.510 \mu \mathrm{m})$ with low surface reflectance enable to recognize the spectral slope, these channels are most important. Therefore these channels are treated with smaller weighting factors $w(\lambda)$ in Eq. (15) than channels 6 and 7 close to "the red edge". The weighting factor scales spectrally the iterative change of the surface reflectance, thus it determines the 


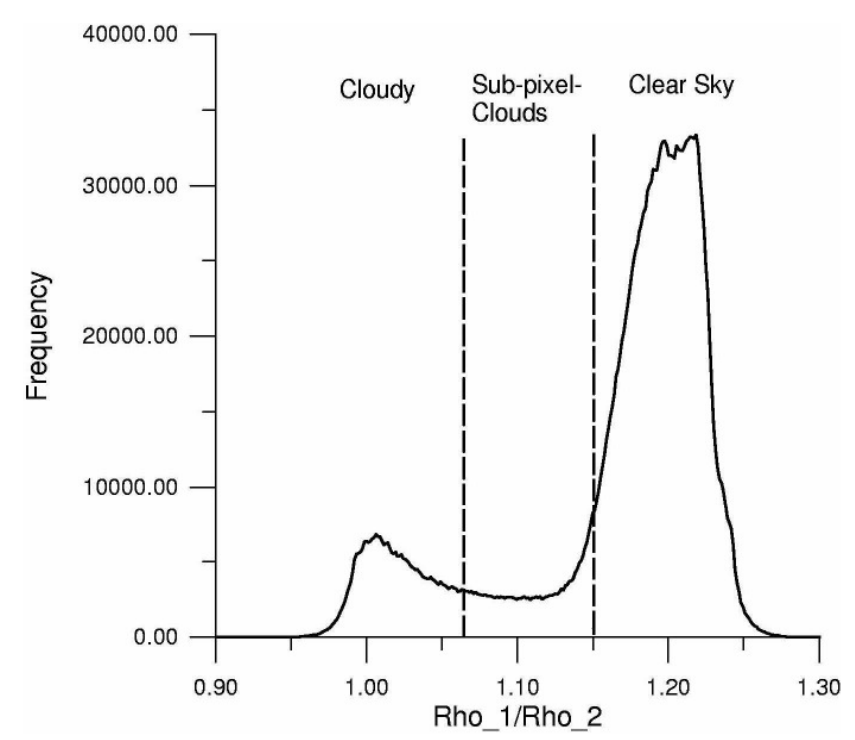

Fig. 10. Example of a histogram of the ratio $R=\rho_{\mathrm{TOA}}$ $(0.412 \mu \mathrm{m}) / \rho_{\mathrm{TOA}}(0.443 \mu \mathrm{m})$ of a real satellite scene. The ratio value, discriminating the clear sky range is used for cloud screening.

convergence of the iteration. The weighting factors were determined empirically to reach a fast enough and sufficiently stable convergence of the iteration procedure. In channel 5 at $0.560 \mu \mathrm{m}$ an insufficient separation of the vegetation peak is found. The vegetation peak at this wavelength is highly variable and this variability is not well considered by the linear mixing model of the spectral surface reflectance (Eq. 6) using one spectrum for "green vegetation" and "bare soil" only. This was the reason for increased AOT in this channel and consequently systematic decreased Angström $\alpha$. Therefore this channel is associated with an increased weighting factor $w(\lambda)$.

\subsection{Cloud screening in BAER}

Really cloud free conditions are very important for the retrieval of AOT, because the approach described above, is valid for cloud free conditions only. Therefore a pre-step for the AOT retrieval is a rigorous cloud screening. Unconsidered clouds increase the retrieved AOT and change their spectral behaviour. This is very relevant, if temporal averages are required. One non-recovered cloud can bias the average for one month significantly.

Since MERIS and SeaWiFS do not have channels in the thermal IR, the cloud screening uses cloud properties in the VIS channels of the instruments for their discrimination.

Based on main cloud properties: (1) clouds are bright, e.g. cloudy pixels have an increased TOA reflectance, (2) clouds have a spectrally neutral reflectance, (3) clouds are elevated and (4) clouds are inhomogeneous, three criteria for the cloud screening have been derived:
1. Pixels are flagged as cloudy, if the TOA reflectance $\rho_{\text {TOA }}$ in $3 \mathrm{SW}$ channels exceeds an assumed minimum cloud reflectance $\rho_{\mathrm{Cl} \text { _Min }}$, obtained from Kokhanovsky (2001): $\rho_{\mathrm{TOA}} \geq \rho_{\mathrm{Cl} \_\mathrm{Min}}$. For nadir conditions and normal aerosol loads we use $\rho_{\mathrm{Cl} \_ \text {Min }}=0.2$. This condition works for fully cloudy pixels. It has limits for strongly increased aerosol loading (strong urban pollution, desert dust storms, plumes of forest fires). In this case $\rho_{\mathrm{Cl} \_ \text {Min }}$ has to be increased. It is not sufficient for low fractional cloud coverage. For this purpose clouds should be "white" in a RGB plot, while aerosols deviate from "white".

2. A decreased spectral slope of TOA reflectance indicates thin clouds and fractional cloud coverage below $\rho_{\mathrm{Cl}}$ Min. The characterization of the spectral slope is made by the ratio of channel 1 and $2: R=\rho_{\text {TOA }}(0.412 \mu \mathrm{m}) / \rho_{\text {TOA }}$ $(0.443 \mu \mathrm{m})$. The analysis of this ratio for scenes over Europe for cloudy and cloud free scenes. One example is presented in Fig. 10. The partly cloudy scenes are removed using the criterion $R>1.15$.

3. Since clouds are inhomogeneous the ratio of standard deviation $\left(\sigma_{5 \times 5}\right)$ to average of $\rho_{\mathrm{TOA}}\left(\operatorname{AV}\left(\rho_{\mathrm{TOA}}\right)_{5 \times 5}\right)$ or AOT $\left(\mathrm{AV}(\mathrm{AOT})_{5 \times 5}\right)$ is used to characterize the spatial variability within a $5 \times 5$ pixel box for the retrieved spectral channels. If $R_{\mathrm{V}}=\sigma_{5 \times 5} / \mathrm{AV}>0.10$, then a scene is taken as cloudy. For low AOT an increased boarder needs to be selected.

All three criteria together remove the most cloud effects. However, not all criteria can be applied everywhere and for every case. For instance, over bright desert ground $\rho_{\mathrm{Cl} \_\mathrm{Min}}$, criterion 1 has to be increased. If bright grounds are elevated, $R$ under criterion 2 needs to be decreased. A very low AOT $(<0.1)$ requires an increased $R_{\mathrm{V}}$, because of heterogeneity of land surface. Therefore bright grounds, like snow and ice cover, also very bright bare soil regions are excluded.

Other effects, connected with clouds are cloud shadows. Cloud shadows cause too low AOT values (even sometimes a negative ones). For the detection of cloud shadows two indicators are applied.

1. One fraction of cloud shadows occur within areas of scattered clouds and increases the standard variation and will be removed by the analysis of the inhomogeneity (criterion 3).

2. Secondly cloud shadows reduce the atmospheric scattering and surface reflection. The case having a TOA reflectance lower than Rayleigh path reflectance, $\rho_{\text {TOA }}<$ $\rho_{\text {Ray }}$, is a clear indication for cloud shadows.

Since the cloud products of standard satellite data products (like cloud fraction or cloud flagging) do not cover the case of totally cloud free sky in a sufficient way for an aerosol retrieval, the application of all criteria above for clouds and 

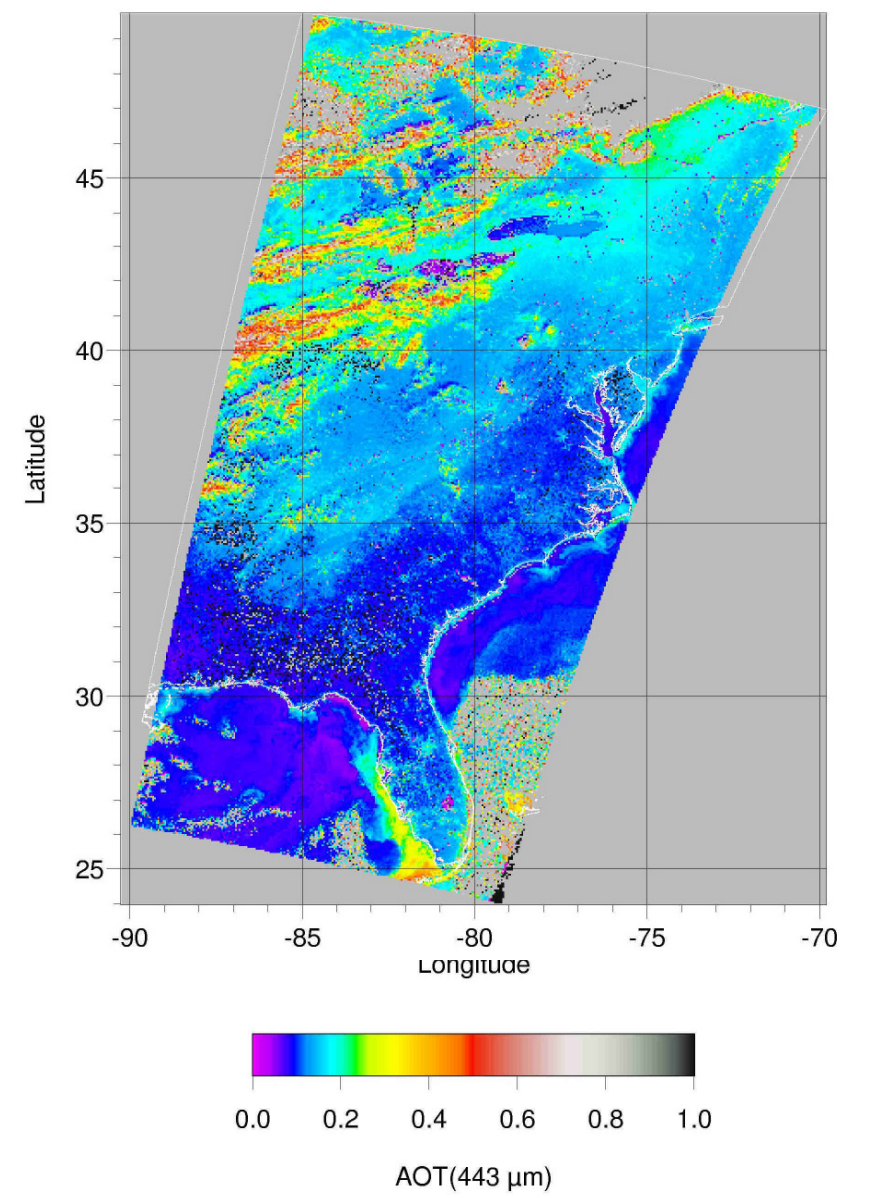

Fig. 11. Retrieval of AOT at $0.443 \mu \mathrm{m}$ for a clear day over eastern US on 21 November 2003, 15:48 UTC. Aerosol source regions can be identified. New York, Philadelphia, Washington and some other urban areas in Florida can be identified with an increased AOT of about 0.07 to 0.1 compared to the surrounding conditions. Near the South-East coast of Florida disturbances from "case 2" - water with sediment content can be seen as apparently increased AOT.

cloud shadows is recommended. The criteria above are investigated and tested within the MICROS approach for the determination of synergetic cloud fration algorithm, presented by Schlundt et al. (2010).

\subsection{BAER versions}

The approach described above exists in different realizations depending on instrument and input data products (see Table 4). Thus the program can be used for MERIS RR (reduced resolution) and MERIS FR (full resolution) data. Here all spectral MERIS channels are used, except those having strong gaseous absorption by $\mathrm{O}_{2}$ (channel 11) and water vapour (channel 15)-13 channels in total can be used. Thus 7 channels below the "red edge" can be used for the determination of the spectral AOT $(0.412-0.670 \mu \mathrm{m})$ and the NIR channel at $0.865 \mu \mathrm{m}$ additionally is used additionally for
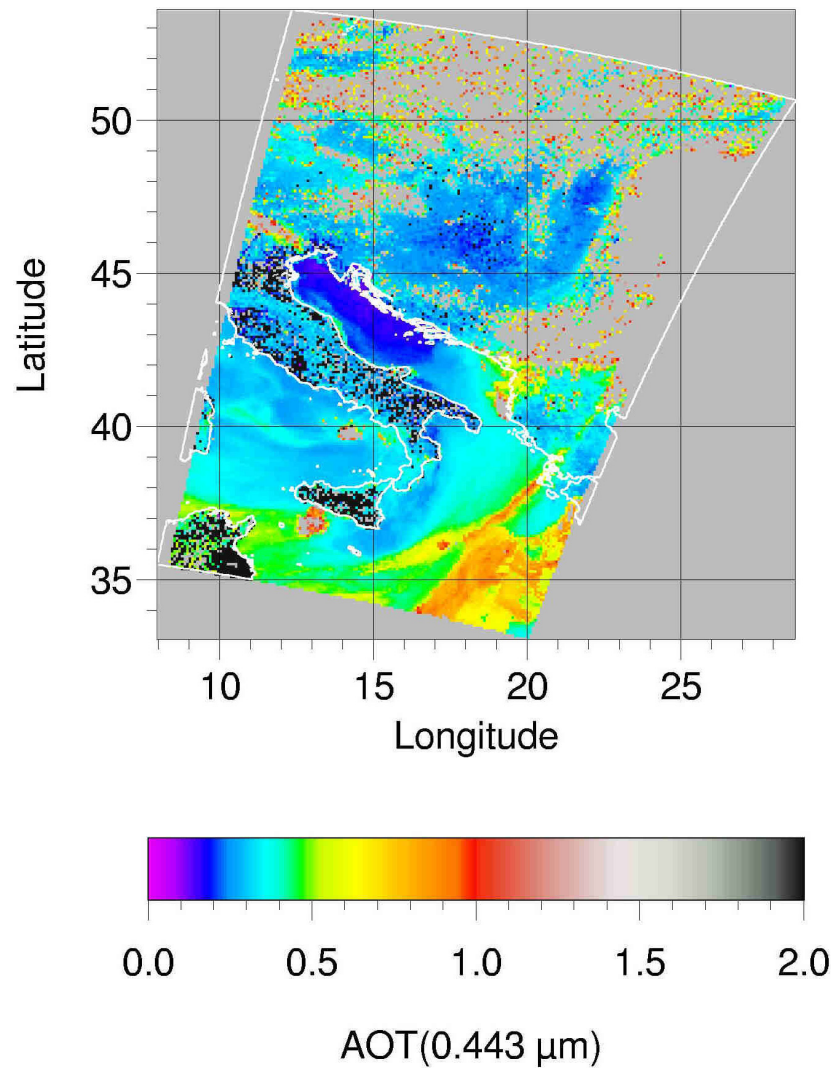

Fig. 12. Smoke plumes of the large forest fires in Greece of summer 2007, MERIS RR scene of 26 August 2007, 09:21 UTC. Several forest fires at the Greek and Albanian coasts can be identified and the aerosol transport along the trajectories to the south - west can be observed. Thus satellite observations enable the control of pollution even there, where no direct observations are available.

the NDVI. Both versions extrapolate then the AOT for all MERIS channels and perform a complete atmospheric correction for them, giving additionally surface directed spectral reflectance. In the case of $\mathrm{L} 1$ data, the TOA radiance, given by the $\mathrm{L} 1$ product, is transferred into TOA reflectance and the BAER approach is used as described above.

In the case of L2 data, the Rayleigh corrected reflectance is used, given by the $\mathrm{L} 2$ data product. The $\mathrm{L} 2$ data product provided by ESA, do not contain the complete atmospheric correction over land. The processing of the product considers only the Rayleigh path reflectance. In this case the step of correction of Rayleigh path reflectance is omitted in BAER. This version completes atmospheric correction over land for the L2 data and is available as a plug-in for the BEAM toolbox, provided by ESA, BEAM (2007).

A version running with a reduced channel setting can be applied for different satellite instruments, having the main channels of ocean colour instruments, e.g. 6 channels below the "red edge" and the $0.865 \mu \mathrm{m}$ for the determination of NDVI - 8 channel version. It can be used for MERIS L1 


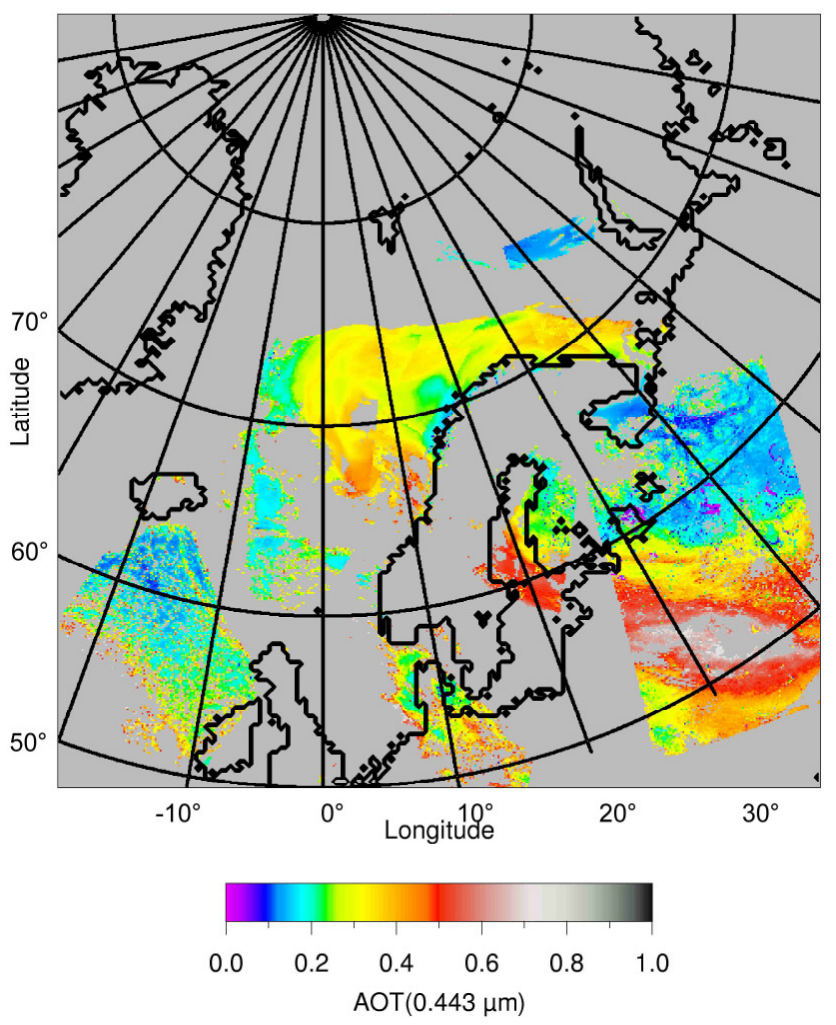

Fig. 13. Composite of MERIS AOT retrievals at the wavelength $0.443 \mu \mathrm{m}$ for 3 orbits of MERIS RR data over northern Europe for 1 May 2006, showing pollution transport around a high pressure system over northern Russia. The scene shows a large scale pollution transport from Europe to the Arctic, causing arctic haze. The atmospheric conditions and the study of pollution transport is discussed in detail by Treffeisen et al. (2007). The highest values of AOT in the pollution plume over Russia are screened out by the cloud screening, also scattered clouds are not removed totally, because not all criteria of the cloud screening have been applied.

RR, MERIS L1, FR, SeaWiFS LAC (local area cover), SeaWiFS GAC (global area cover). MODIS data can be used, if the first ocean colour channels do not reach saturation over land.

\section{Results and validation}

\subsection{Results of AOT retrievals}

For the demonstration of the capabilities of the approach, described above, some examples of AOT retrievals are shown. We concentrate here on results for channel $2(0.443 \mu \mathrm{m})$, because this channel has a low retrieval error. All retrievals have been made with the same LUT, No. 6 of Table 3 . This LUT is selected, if no specific a-priori knowledge of the existing aerosol type is known. It is found, that in the most cases this LUT gives reliable results, as can be seen in Sect. 4.2 on validation.

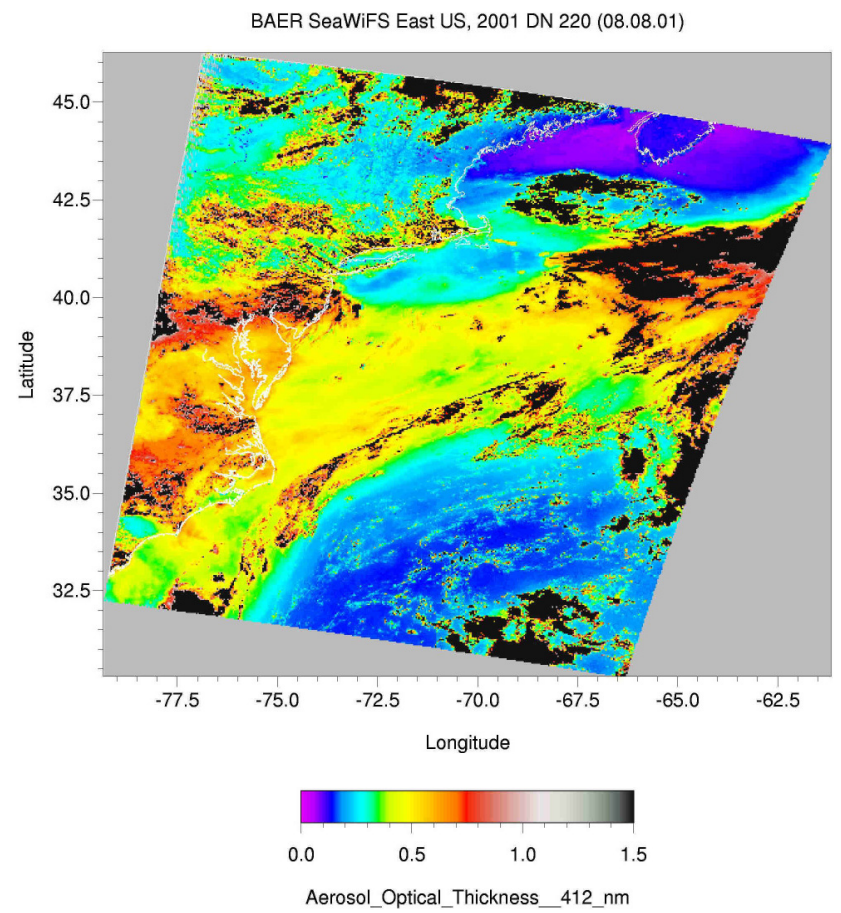

Fig. 14. AOT of channel $1-0.412 \mu \mathrm{m}$, showing pollution transport from Eastern US towards the Atlantic ocean, 8 August 2001, observed with SeaWiFS. SeaWiFS L1b LAC data of GSFC receiving station and BAER 8-channel version are used.

The selected scenes of MERIS data are part of validation data sets for the validation results in Sect. 4.2. They show cases of low aerosol loading over Eastern US (Fig. 11) and high ones during Greek fire season in 2007 (Fig. 12). More detailed explanations are given within the figure captions.

As single scene (about 8 min of MERIS data) - a part of one orbit can be processed with a normal desktop personal computer. Larger scenes need to be split into smaller parts for processing and composed from the fractions. Examples of composites of more scenes and orbits are presented in Figs. 13 and 21.

Scenes of SeaWiFS data are presented in Figs. 14 and 21 , to demonstrate the capability of the 8 channel version of BAER. Figure 14 shows aerosol transport from Eastern US to the Atlantic and Fig. 21 a daily composite of an AOT retrieval, using SeaWiFS GAC data for the globe.

Further a normal case of aerosol loading over Germany is selected in Fig. 15 to present spectral AOT. The surface reflectance data of the retrieval are given in Fig. 16.

The selected scenes should give examples, how the approach can be applied for the observation of the regional aerosol impact in terms of the AOT as well over land as over ocean. Thus such aerosol retrievals can contribute to environmental control of air pollution by aerosols, especially, if additional aerosol products, like PM10 concentrations are derived from AOT, as it is done by von Hoyningen-Huene et al. (2008). 


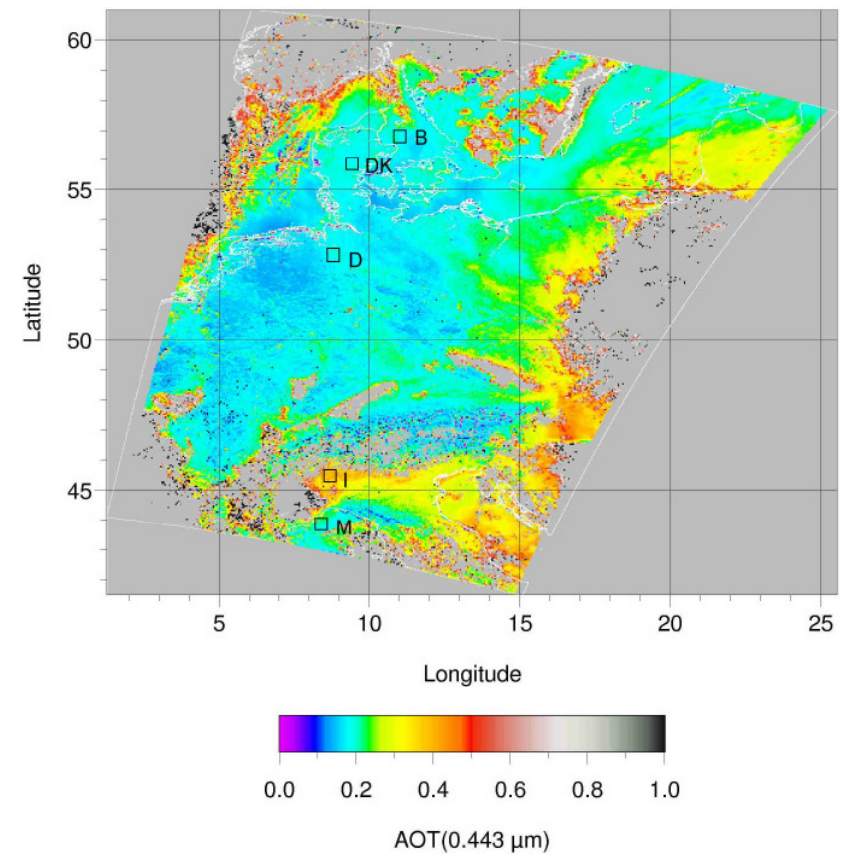

Fig. 15. Retrieval of AOT at $0.443 \mu \mathrm{m}$ over Germany and surrounding areas, using MERIS RR L1 data of 13 October 2005, 09:54 UTC, showing average autumnal aerosol loading. Pollution in the valley of the river Po in northern Italy is visible. Increased AOT also is seen in the vicinity of the large cloud system at the east side of the swath, probably caused by cloud influence.

Pollution in the valley of the river Po in northern Italy is visible in Fig. 15. Increased AOT also can be seen in the vicinity of the large cloud system at the east side of the swath, probably caused by cloud influence.

The scene given in Fig. 15 is used to present the retrieval data more in detail, e.g. spectral AOT and spectral surface reflectance in Fig. 16. Rectangles in Fig. 15 indicate locations, where spectra of AOT have been selected. Three land sites, DK - Denmark (near Kolding), D - Germany (near Bremen), I - Italy (Po valley near Milan) have been selected, where both, AOT and surface reflectance are given. Additionally two sea sites have been selected for the spectra of surface reflectance: B - Baltic Sea and M - Mediterranean. The spectral surface reflectance in Fig. (16b) is the result of the atmospheric correction, applying spectral AOT to correct for the effect of aerosol reflectance. The spectra over Denmark and Germany are typical for dark dense vegetation without free bare soil fractions. The spectra over Italy are typically for only fractional vegetation coverage, where the surface reflectance is partly determined by bare soil.

\subsection{Validation of AOT and error estimation}

Validation and evaluation of the retrieval approach is made by different ways: (a) inter-comparison of the AOT results with ground based AERONET data, Holben et al.,
2001 and (b) retrievals with synthetic test data, provided by Kokhanovsky et al. (2010).

(a) Inter-comparison with ground-based AERONET data.

For the BAER application with MERIS L1 data a validation against AERONET data has been made. Since the focus of our retrievals is mainly on Europe, 28 AERONET sites over Europe have been selected. Additional 9 sites in eastern US and Canada are included within this study. Figure 17 indicates the positions of the validation sites, the names of the sites are provided in Table 5. Cloud screened level 2 (or if not available level 1.5) AERONET data have been used within a time $\pm 1 \mathrm{~h}$ around the MERIS overflight time. Arbitrary cloud free MERIS scenes of different project studies and measurement campaigns within the time 2003 and 2006 have been used for comparisons with the ground-based data.

The retrieval procedure contains a data set with the geographic coordinates of the validation sites and within a circle of $0.03^{\circ}$ around these coordinates. Average and standard deviation of AOT is taken from the retrieval results. This is compared with the ground based AOT data of the associated AERONET site within a time interval of $\pm 1 \mathrm{~h}$. Since AERONET provides AOT data for the wavelengths 0.44, $0.67,0.87$ and $1.02 \mu \mathrm{m}$, the first study was made with MERIS channel $2(0.443 \mu \mathrm{m})$ in a direct inter-comparison.

The results of these inter-comparisons for the MERIS channel $2(0.443 \mu \mathrm{m})$ are presented in Fig. 18.

The comparison of the retrieved AOT for the wavelength $0.443 \mu \mathrm{m}$ with the AERONET channel of $0.440 \mu \mathrm{m}$ in Fig. 18 shows, that both data sets are correlated. A significant relationship between retrieved AOT and AERONET derived AOT is found as

$$
\begin{aligned}
\delta_{\text {Aer,MERIS }}(0.443 \mu \mathrm{m})= \\
0.866 \cdot \delta_{\text {Aer,AERONET }}(0.440 \mu \mathrm{m})+0.051
\end{aligned}
$$

with a correlation coefficient of $r=0.961$. The average deviation of the retrievals from the regression line for this data set is 0.052 . Thus the retrieval error of AOT for the channel $0.443 \mu \mathrm{m}$ can be estimated as $\Delta \delta_{\text {Aer }}(0.443 \mu \mathrm{m})= \pm 0.05$. This is for an average AOT of 0.2 an error of $25 \%$.

With a smaller data set the same study for MERIS channel $7(0.665 \mu \mathrm{m})$ is performed with AERONET channel of $0.67 \mu \mathrm{m}$ over Europe only. Because of the lower AOT values the error of the retrieval is increased and the correlation is weaker. The correlation coefficient is $r=0.832$ and the relative error reaches there $35 \%$.

Since BRDF effects have a stronger effect on AOT for larger wavelengths than for shorter ones (increased surface reflectance and smaller AOT), the consideration of BRDF increases the Angström $\alpha$ parameter and leads to smaller AOT for the $0.665 \mu \mathrm{m}$ wavelength. This could reduce the error for $0.665 \mu \mathrm{m}$. The effects of BRDF are still under investigation.

(b) Inter-comparison with synthetic test data.

Simulated TOA reflectance data, obtained by SCIATRAN (Rozanov et al., 2001, 2005) have been provided by 

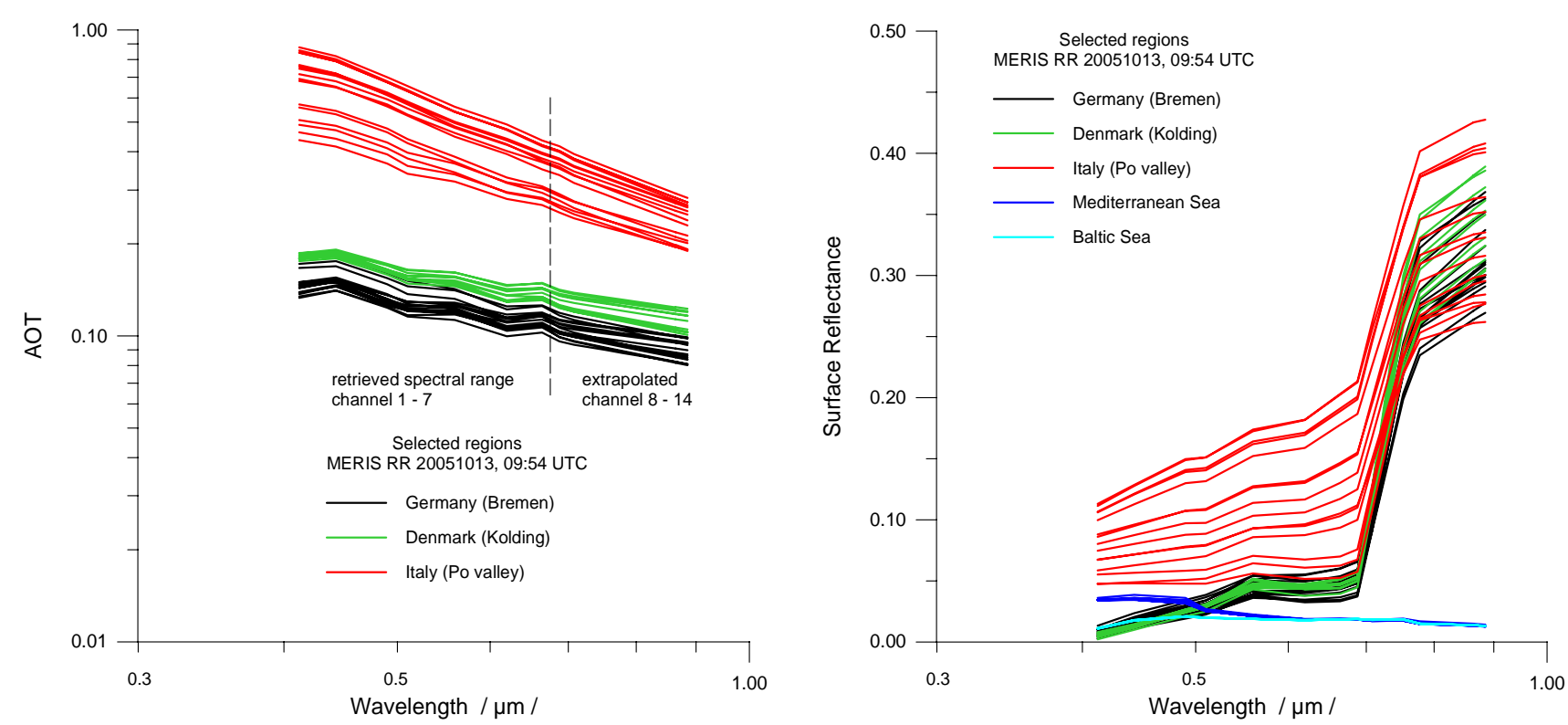

Fig. 16. (a) left - retrievals of spectral AOT of the MERIS RR scene of 13 October 2005, 09:54 UTC for the selected regions in Fig. 14: Denmark (near Kolding), Germany (near Bremen), Italy (Po valley near Milan). (b) right - spectral surface reflectance for all sites and additionally for sites over the Baltic Sea and Mediterranean.

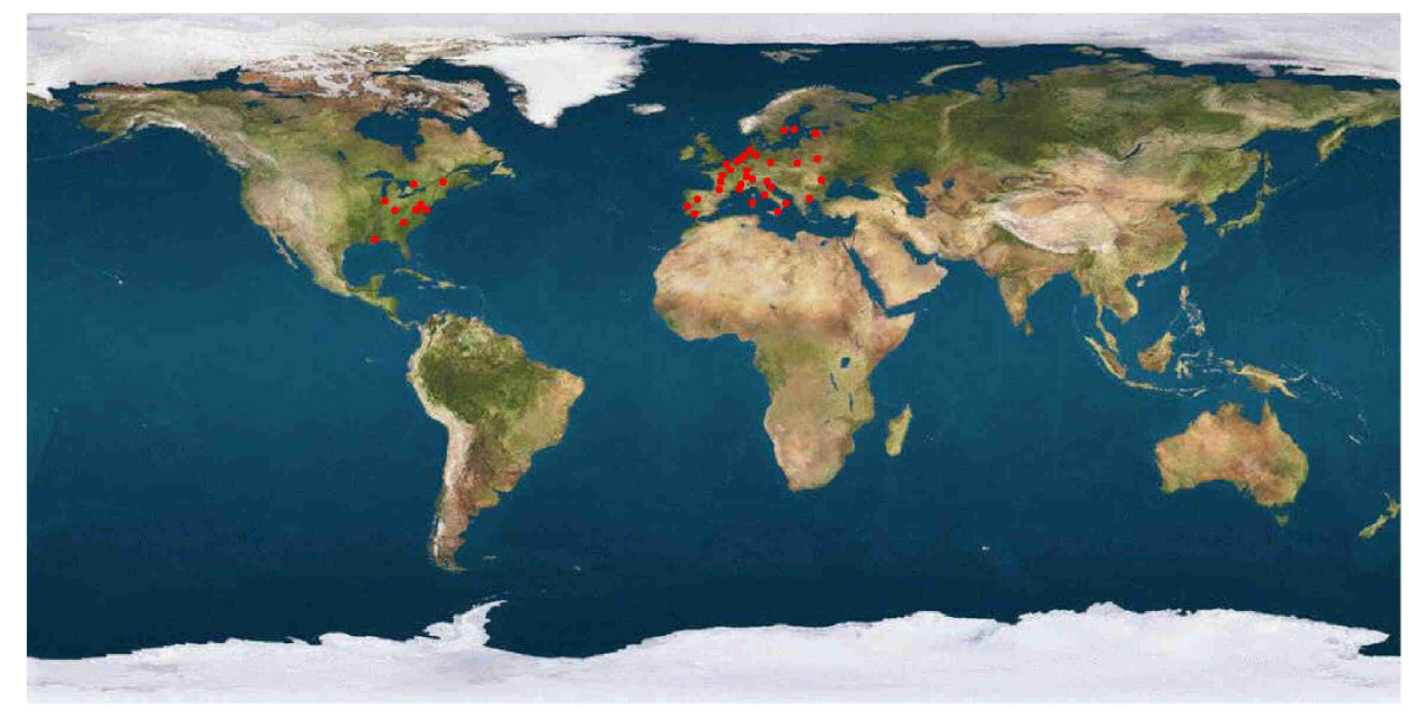

Fig. 17. Location of validation sites of AERONET, used for the inter-comparison of AOT retrievals from MERIS L1 data with ground based measurements of AOT.

Kokhanovsky et al. (2010) for the test of aerosol retrieval algorithms. The modelled data of TOA reflectance were provided for conditions of "black" surface for an "unknown" aerosol type and a given illumination and viewing geometry $\left(z_{0}=60^{\circ}, z_{S}=0^{\circ}\right)$ for a range of unknown values of AOT, which should be retrieved. Figure 19 presents the results of AOT retrieval with the given AOT used for the radiative transfer modelling. The results of the inter-comparison give very different results depending on the selected phase func- tion and corresponding LUT. Using the LUT with the experimental LACE-98 phase function, which gave in the intercomparison with the AERONET data the best results, a large underestimation of AOT has been obtained, using the modeled test data. Selecting a-priori the LUT for clean marine aerosol a quite good correspondence of the AOT retrieval has been found. The phase function of the clean marine model coincides with that phase function used for the modeling of synthetic TOA reflectance data. The phase functions 
Table 4. Overview of BAER versions.

\begin{tabular}{|c|c|c|c|}
\hline Input data & BAER version & Results & Remarks \\
\hline MERIS L1 RR & $\begin{array}{l}13 \text { channel } \\
\text { version }\end{array}$ & $\begin{array}{l}\text { AOT for MERIS } \\
\text { channels } 1-7 \\
\text { Surface reflectance for } \\
\text { channels } 1-10,12-14\end{array}$ & $\begin{array}{l}\text { Spatial resolution } \\
1.1 \times 1.1 \mathrm{~km}^{2}\end{array}$ \\
\hline MERIS L1 FR & $\begin{array}{l}13 \text { channel } \\
\text { version }\end{array}$ & $\begin{array}{l}\text { AOT for MERIS } \\
\text { channels } 1-7 \\
\text { Surface reflectance for } \\
\text { channels } 1-10,12-14\end{array}$ & $\begin{array}{l}\text { Spatial resolution } \\
0.3 \times 0.3 \mathrm{~km}^{2}, \text { same } \\
\text { program code as above }\end{array}$ \\
\hline $\begin{array}{l}\text { MERIS L1 RR } \\
\text { SeaWiFS LAC } \\
\text { (MODIS) }\end{array}$ & $\begin{array}{l}8 \text { channel } \\
\text { version }\end{array}$ & $\begin{array}{l}\text { AOT for MERIS } \\
\text { channels } 1-5,7 \text { or SeaWiFS } \\
\text { channels } 1-6\end{array}$ & $\begin{array}{l}\text { Spatial resolution } \\
1.1 \times 1.1 \mathrm{~km}^{2}\end{array}$ \\
\hline SeaWiFS GAC & $\begin{array}{l}8 \text { channel } \\
\text { version }\end{array}$ & $\begin{array}{l}\text { AOT for SeaWiFS } \\
\text { channels } 1-6\end{array}$ & $\begin{array}{l}\text { Spatial resolution } \\
4.5 \times 4.5 \mathrm{~km}^{2}\end{array}$ \\
\hline MERIS L2 RR & $\begin{array}{l}13 \text { channel } \\
\text { version }\end{array}$ & $\begin{array}{l}\text { AOT for MERIS } \\
\text { channels } 1-7 \\
\text { Surface reflectance for } \\
\text { channels } 1-10,12-14\end{array}$ & $\begin{array}{l}\text { Spatial resolution } \\
1.1 \times 1.1 \mathrm{~km}^{2} \text {, completion } \\
\text { of atmospheric correction of } \\
\text { MERIS L2 product over land }\end{array}$ \\
\hline
\end{tabular}

Table 5. AERONET sites used in validation studies of BAER. Latitudes and longitudes are given in degrees.

\begin{tabular}{|c|c|c|c|c|c|c|c|c|}
\hline $\begin{array}{l}\text { Europe } \\
\text { Location }\end{array}$ & Lat. & Lon. & $\begin{array}{l}\text { North America } \\
\text { Location }\end{array}$ & Lat. & Lon. & $\begin{array}{l}\text { Other regions } \\
\text { Location }\end{array}$ & Lat. & Lon. \\
\hline Avignon & 43.933 & 4.878 & Cartel X & 45.379 & -71.931 & Anmyon & 126.267 & 126.267 \\
\hline Dunkerque & 51.035 & 2.368 & Columbia SC & 34.023 & -81.036 & Ascension & -7.883 & -14.417 \\
\hline Bremen (IUP Cimel) & 53.05 & 8.78 & Cove & 36.900 & -75.710 & Azores & 38.530 & -28.630 \\
\hline Cabauw & 51.971 & 4.927 & Egbert & 44.226 & -79.750 & Bamizoubou & 13.541 & 2.665 \\
\hline DenHaag & 52.110 & 4.327 & GSFC & 39.030 & -76.880 & Cabo-Verde & 16.733 & -22.935 \\
\hline El-Arenosillo & 37.105 & -6.733 & MD Science Center & 39.283 & -76.618 & Ilorin & 8.320 & 4.340 \\
\hline Evora & 38.568 & -7.912 & Walker Branch & 35.958 & -84.284 & Midway & 28.220 & -177.170 \\
\hline Fontaibleau & 48.407 & 2.680 & Wallops Island & 37.942 & -75.475 & Ouagadogou & 12.200 & -1.400 \\
\hline Ft. Crete & 34.656 & 22.129 & & & & Praja & 14.974 & -23.484 \\
\hline Gotland & 57.917 & 18.950 & & & & SantaCruz & 28.660 & -16.330 \\
\hline Hamburg & 53.586 & 9.973 & & & & Thala & 35.550 & 8.683 \\
\hline Helgoland & 54.178 & 7.887 & & & & & & \\
\hline ISGDM-CNR & 45.437 & 12.332 & & & & & & \\
\hline Ispra & 45.803 & 8.627 & & & & & & \\
\hline Karlsruhe & 49.093 & 8.428 & & & & & & \\
\hline Europe (continued) & & & & & & Europe (continued) & & \\
\hline Laegeren & 47.480 & 8.351 & & & & Oristano & 40.307 & 7.906 \\
\hline Lampedusa & 35.517 & 12.632 & & & & Palaiseau & 48.700 & 2.208 \\
\hline Lecce & 40.335 & 18.111 & & & & Paris & 48.867 & 2.333 \\
\hline Leipzig & 51.354 & 12.435 & & & & Rome & 41.840 & 12.647 \\
\hline Lille & 50.612 & 3.142 & & & & Stockholm & 58.580 & 16.150 \\
\hline Mainz & 49.999 & 8.300 & & & & Toravere & 58.255 & 26.468 \\
\hline Messina & 38.197 & 15.567 & & & & Toulon & 43.136 & 6.009 \\
\hline Modena & 44.632 & 10.945 & & & & Venise & 45.314 & 12.508 \\
\hline Oostende & 51.225 & 2.925 & & & & & & \\
\hline
\end{tabular}




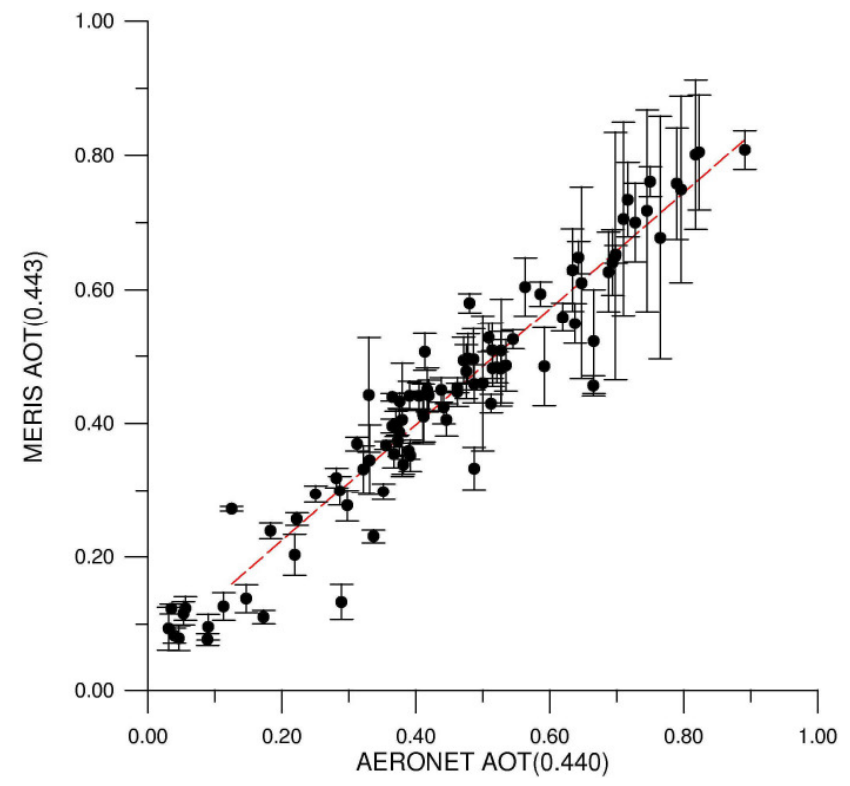

Fig. 18. Validation of BAER AOT retrievals using MERIS L1 data for the wavelength $0.443 \mu \mathrm{m}$ against AERONET channel $0.440 \mu \mathrm{m}$ for collocated data over European and US sites.

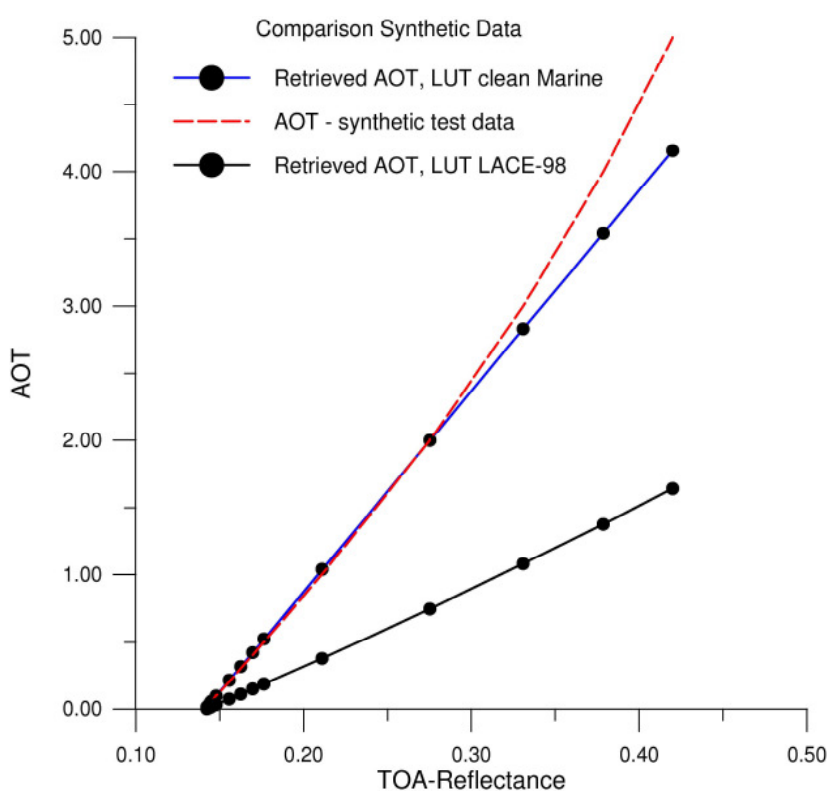

Fig. 19. Synthetic data retrieval. BAER retrieval results for two different phase functions: experimental LACE-98 and OPAC clean marine, using synthetic test data of Kokhanovsky et al. (2010). The dashed line is the plot of the synthetic test data.

used for the test retrievals and the synthetic data are plotted in Fig. 7. The different results underline the importance of the selection of the appropriate phase function in BAER. The disagreement of the retrieval results from the synthetic data, using LUT with the LACE-98 phase function, and on
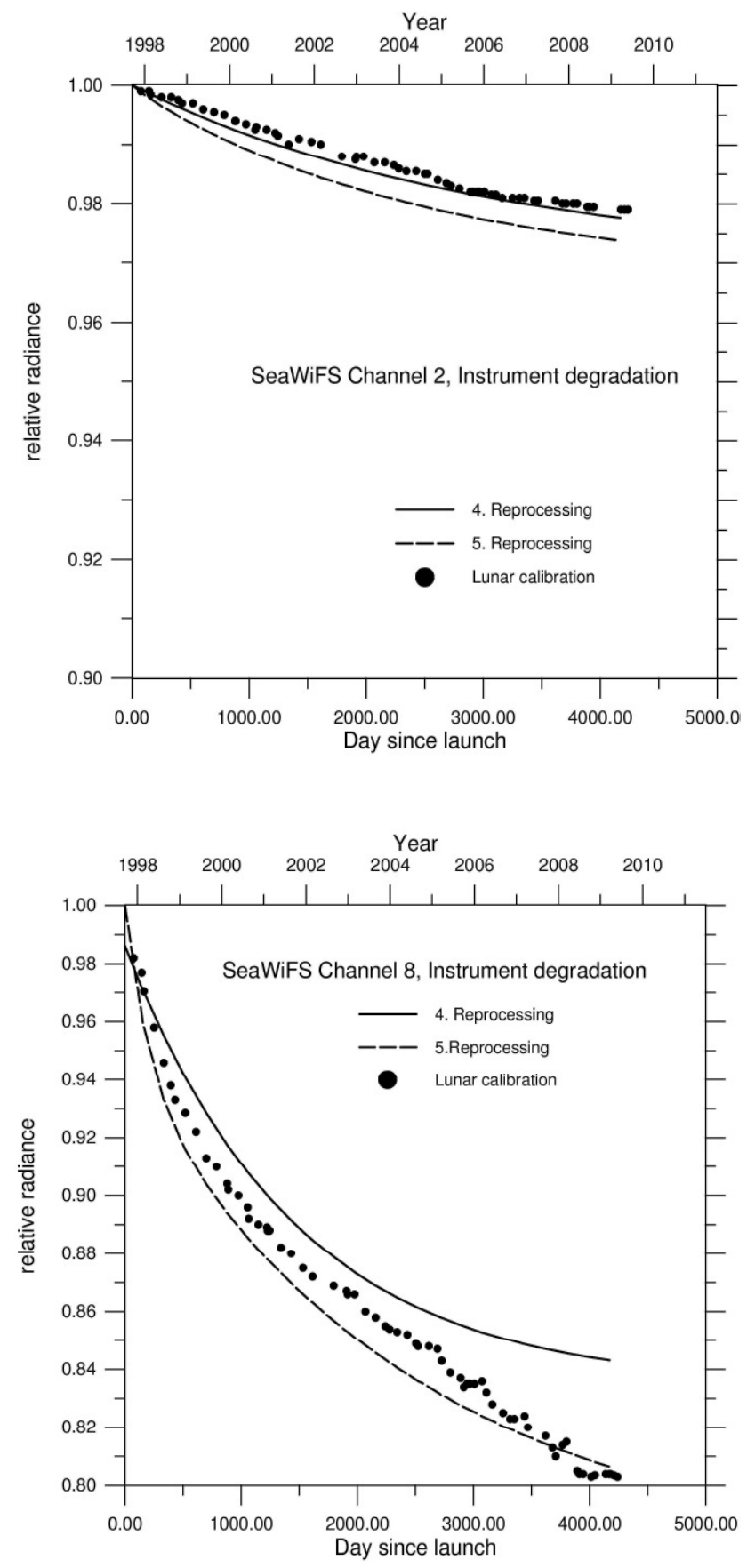

Fig. 20. Instrument degradation according 4. and 5. reprocessing in comparison with the lunar calibration of the SeaWiFS instrument.

the other hand their quite good agreement with AERONET data, shows, that this synthetic data did not characterize the majority of real observation conditions. 


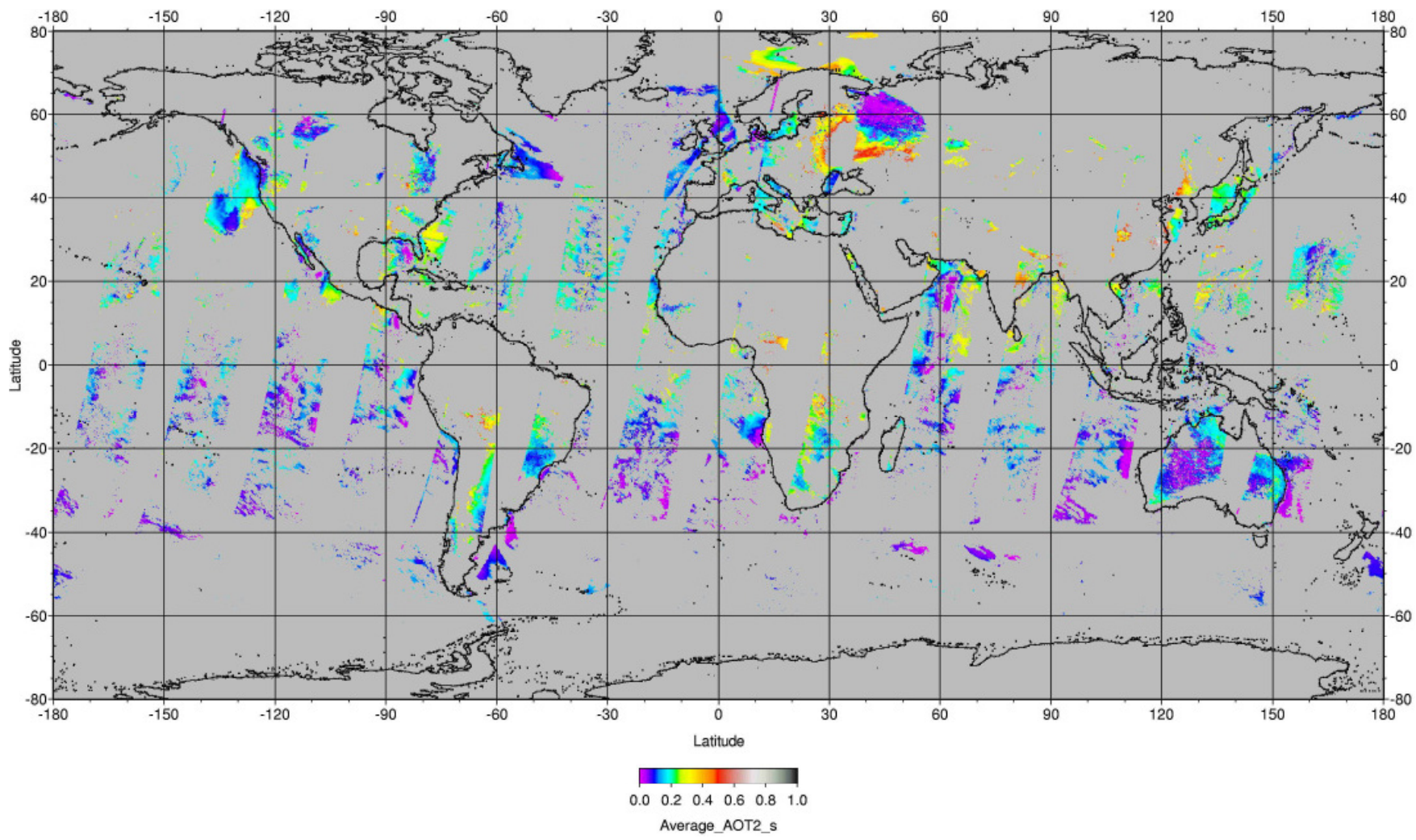

Fig. 21. Daily AOT product for the globe of 3 May 2006, obtained by BAER, using SeaWiFS GAC data for the generation of monthly averages.

\subsection{First estimation of trends in AOT from SeaWiFS observations}

The method described in Sect. 3 has been applied to the longterm data series of SeaWiFS Global Aerea Cover (GAC) data. The SeaWiFS data were available since October 1997 up to now. The presented and analysed here time span was October 1997-May 2008. The investigation of such a time span requires the consideration of the degradation of the SeaWiFS instrument, done by the SeaWiFS calibration team of NASA, providing the calibration functions to calculate the radiance from the measured counts by the instrument. The degradation behaviour, given for the 5-th SeaWiFS reprocessing, is used, see examples for channel 2 and 8 in Fig. 20, to obtain a TOA reflectance free of degradation effects, which could be used then for the application with the BAER approach for the retrieval of AOT. One aerosol phase function (LUT number 6 from Table 3) is used for the whole time series. An example of the daily global aerosol product, which is used for the determination of monthly averages, is given in Fig. 21 for the 3 May 2006. An extended description of the trend determination and its validation will be given in Yoon et al. (2011). First results of long-term AOT retrieval for some of the regions of interest of the CITYZEN project (7. Framework Programme of the European Commission) are presented here. Selected regions of interest of this research program were under others: BeNeLux-big (Begium, Netherlands, Luxemburg and Rhein-Ruhr region of Germany: $1^{\circ} \mathrm{E}-$ $8^{\circ} \mathrm{E}, 48^{\circ} \mathrm{N}-54^{\circ} \mathrm{N}$ ), Po-Valley - big (Northern Italy: $7.5^{\circ} \mathrm{E}-$ $13.5^{\circ} \mathrm{E}, 44^{\circ} \mathrm{N}-46^{\circ} \mathrm{N}$ ), Eastern Europe (OECD definition, $18^{\circ} \mathrm{E}-60^{\circ} \mathrm{E}, 40^{\circ} \mathrm{N}-65^{\circ} \mathrm{N}$ ) and Pearl River Delta (in China: $\left.112^{\circ} \mathrm{E}-115.5^{\circ} \mathrm{E}, 22^{\circ} \mathrm{N}-24^{\circ} \mathrm{N}\right)$. All SeaWiFS observations of the regions have been used for the AOT retrieval for the SeaWiFS channels 1-6. Then monthly averages of AOT have been determined from the retrievals. The time series of the monthly averages of AOT for the four regions of interest are given in Fig. 22. The monthly averages of AOT show a distinct annual cycle, like also comparable AERONET data with increased AOT in summer months and lower values for winter. Fitting linear relationships through the retrieved monthly averages let estimate the average annual trend of AOT within the almost 11 year period. The obtained values for the trend are given in Table 6. Data for two channels (0.443 and $0.555 \mu \mathrm{m})$ are presented. Differences in the trends for both wavelengths are due to uncertainties, mainly in surface reflectance. The regions BeNeLux-big and Po-Valley-big show a clear negative trend in AOT over the period of 11 years related to improved air quality within these regions. In the region Eastern Europe within the period almost no trend can be detected. However the region Pearl River Delta in China 


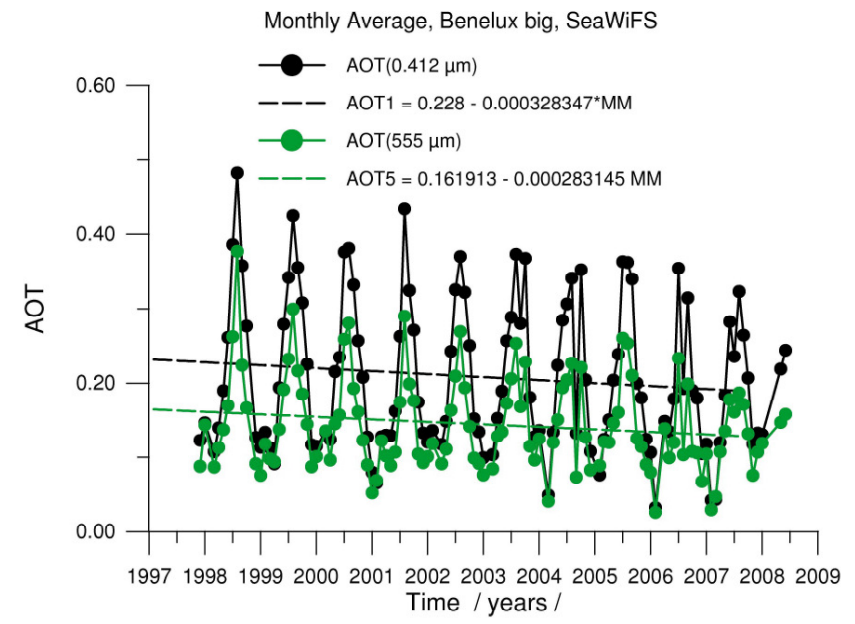

Fig. 22a. Time series of AOT for SeaWiFS channel $1(0.412 \mu \mathrm{m})$ and channel $5(0.555 \mu \mathrm{m})$ for the time span October 1997-May 2008 for the selected regions of interest: BeNeLux-big (Fig. 22a), PoValley-big (Fig. 22b), Eastern Europe (Fig. 22c) and Pearl River Delta (Fig. 22d). Linear fits for the trends of the retrieved AOT are presented as dashed lines.

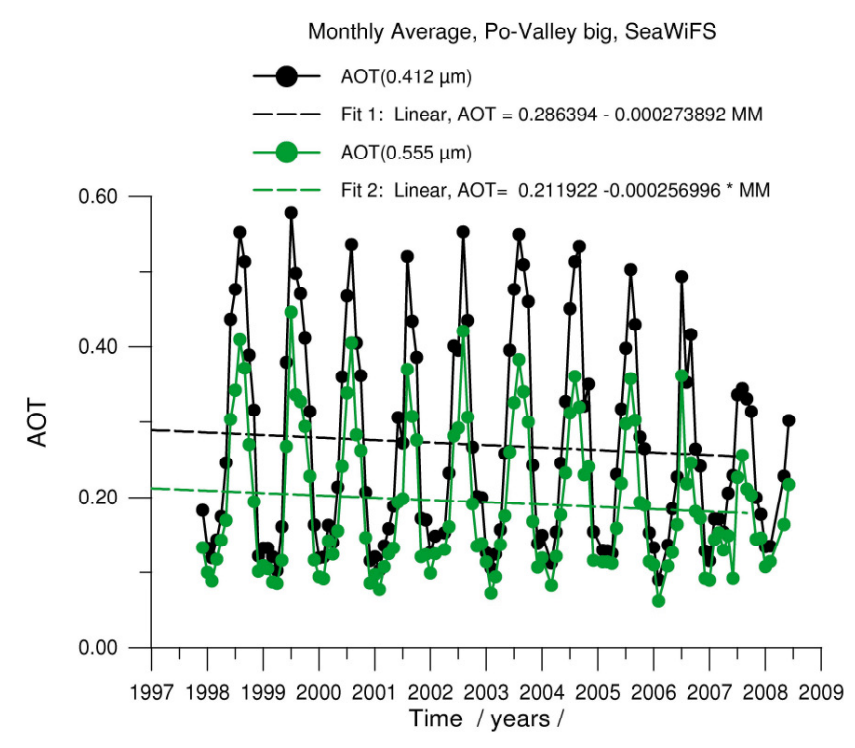

Fig. 22b. Po-Valley-big.

is characterized by a clear increasing trend of AOT. More results and investigation of the significance of the trends will be given by Yoon et al. (2011).

\section{Summary and conclusions}

Bremen AErosol Retrieval (BAER) is a retrieval approach for AOT over land (and ocean) applicable for nadir viewing ocean colour sensors, like MERIS or SeaWiFS. It separates the spectral aerosol reflectance from surface and Rayleigh

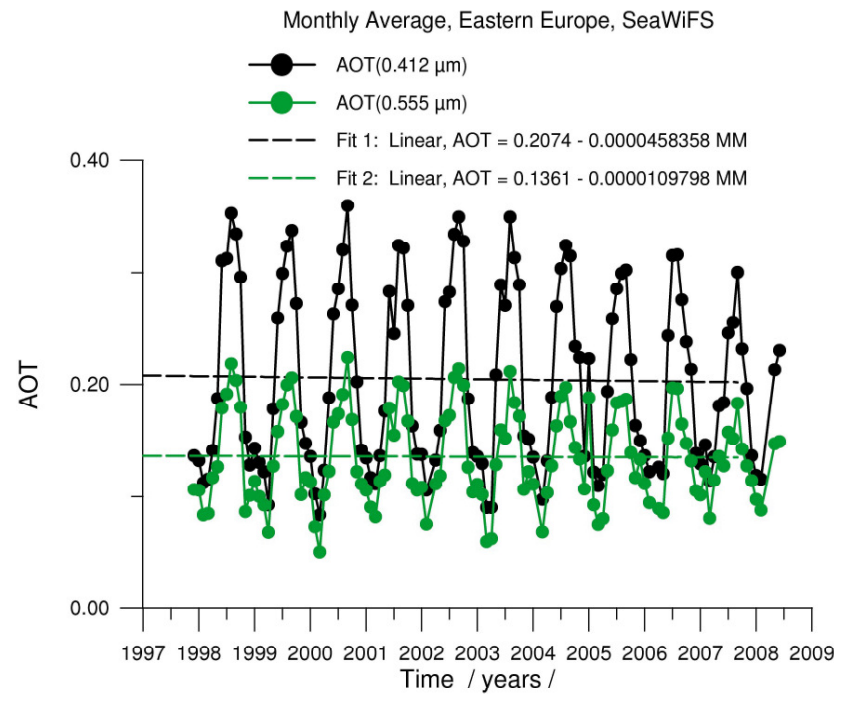

Fig. 22c. Eastern Europe.

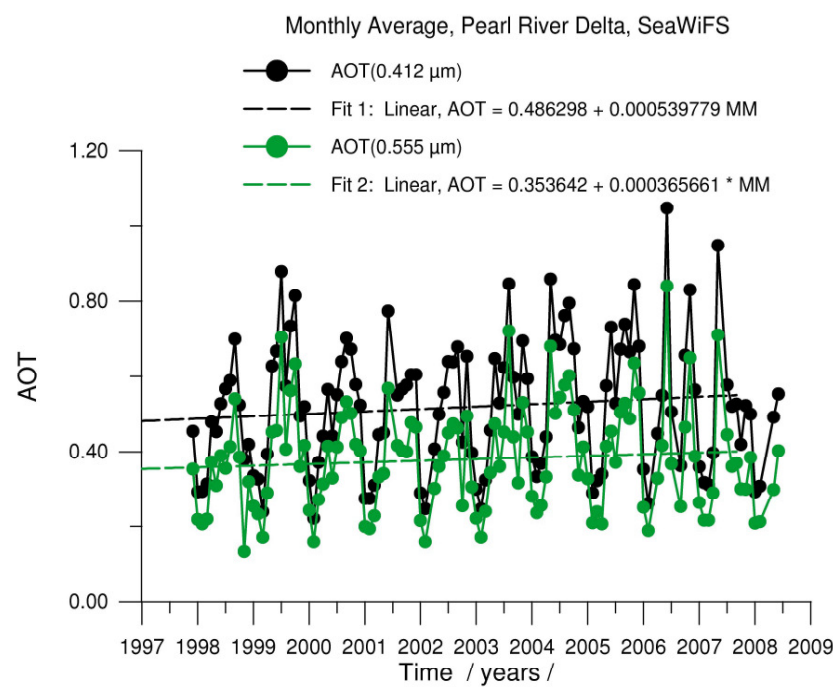

Fig. 22d. Pearl River Delta.

path reflectance for the short wave range of the measured spectrum of top-of-atmosphere reflectance at wavelengths less than $0.670 \mu \mathrm{m}$. The advantage of MERIS is the existence of several spectral channels in the blue and visible range enabling the spectral determination of AOT in 7 channels $(0.412-0.670 \mu \mathrm{m})$ and additionally channels in the NIR, which can be used to characterize the surface properties. A dynamical spectral surface reflectance model for different surface types is used to obtain the spectral surface reflectance for this separation. Normalized differential vegetation index (NDVI), taken from the satellite observations, is the model input. Spectral AOT is obtained from aerosol reflectance using look-up-tables, obtained from radiative transfer calculations with given aerosol phase functions and single scattering 
Table 6. Average annual change in AOT for selected regions of interest.

\begin{tabular}{lrr}
\hline Wavelength/ & $\begin{array}{r}\text { Channel } 1,0.412 \mu \mathrm{m} \\
\Delta \mathrm{AOT}(0.412) / \text { year }\end{array}$ & $\begin{array}{r}\text { Channel } 5,0.555 \mu \mathrm{m} \\
\Delta \mathrm{AOT}(0.555) / \text { year }\end{array}$ \\
\hline Region & -0.0039 & -0.0034 \\
BeNeLux-big & -0.0033 & -0.0031 \\
Eo-Valley-big & -0.00055 & -0.00013 \\
Pearl River Europe & +0.0065 & +0.0044 \\
\hline
\end{tabular}

albedo either from aerosol models, given by OPAC or from experimental campaigns.

Validations of the obtained AOT retrieval results with AERONET data over Europe gave a preference for experimental phase functions derived from sky radiometer almucantar measurements. The validation showed an agreement of AOT with AERONET within 0.05. Further the retrieved AOT does not have sharp contrasts between land and ocean. Thus regional or temporal changes in AOT can be investigated. Using SeaWiFS data, trends in AOT for specific regions are found.

The ocean part of the retrieval approach is not described here. It uses a mixing of "clean water" and "coastal water", tuned by the NDPI (Normalized Differential Pigment Index). For the case of ocean water all channels of MERIS are included.

Separation of angular distribution of light field between surface (BRDF) and atmospheric (aerosol and Rayleigh phase function) effects is one of the major error sources for the AOT retrieval over land. The BRDF influence is still under investigation.

Additional products, based on AOT can be derived. Necessary condition is an accurate retrieval of the spectral AOT. Thus Kokhanovsky et al. (2006) and von Hoyningen-Huene et al. (2008) estimated PM10 concentrations and effective radii of aerosol particles from satellite data, using AOT and Angström $\alpha$ parameter.

Acknowledgements. The authors like to thank ESA EO and NASA ocean colour group for supporting us with satellite observation data. Several ESA, DFG (SAMUM) and EU (CITYZEN) projects were supporting the algorithm development and evaluation. We like to express our gratitude to Robert E. Eplee from NASA for the support considering the SeaWiFS instrument degradation for the long term trends. AERONET service has been used as very valuable source of ground-based validation data. The authors are grateful to the reviewers and editor for important comments on this paper.

Edited by: S. Kinne

\section{References}

Ansmann, A., Wandinger, U., Wiedensohler, A., and Leiterer, U.: Lindenberg Aerosol Characterization Experiment 1998 (LACE 98): Overview, J. Geophys. Res., 107(D21), 8129, doi:10.1029/2000JD000233, 2002.

BEAM: Beam web-page, URL http: envisat.esa.int/services/beam/, 2007.

Bezy, J.-L., Deelwart, S., and Rast, M.: Meris - a new generation of ocean colour sensor onboard Envisat. Technical report EAS Bulletin 103 (2000) 48-56, ESA, 2000.

Buchholz, A.: Rayleigh scattering calculations for the terrestrial atmosphere, Appl. Optics, 34, 2765-2773, 1995.

Cox, C. and Munk, W.: Measurements of the roughness of the sea surface from photographs of the sun's glitter, J. Optical Soc. Amer., 44, 838-850, 1954.

d'Almeida, G. A., Koepke, P., and Shettle, E. P.: Global climatology and radiative characteristics, Deepak, Hampton, 561 p., 1991.

Delwart, S., Bourg, L., and Huot, J. P.: MERIS 1st year: Early calibration results, Proceedings of the International Society for Optical Engineering (SPIE): Sensors, Systems and Next-Generation Satellite VII, Barcelona, Spain, vol. 5234, pp. 379-390, 2003.

Dinter, T., von Hoyningen-Huene, W., Burrows, J. P., Kokhanovsky, A., Bierwirth, E., Wendisch, M., Müller, D., Kahn, R., and Diouri, M.: Retrieval of aerosol optical thickness for desert conditions using MERIS observations during SAMUM campaign, Tellus 61B, 220-237, 2009.

Dubovik, O. and King, M. D.: A flexible inversion algorithm for retrieval of aerosol optical properties from sun and sky radiance measurements, J. Geophys. Res., 105, 20673-20696, 2000.

Dubovik, O., Holben, B. N., Lapyonok, T., Sinyuk, A., Mishchenko, M. I., Yang, P., and Slutsker, I.: Non-spherical aerosol retrieval method emploing light scattering by sheroids, Geophys. Res. Lett., 29(10), 1415, doi:10.1029/2001GL014506, 2002.

Dubovik, O., Sinyuk, A., Lapyonok, T., Holben, B. N., Mishchenko, M., Yang, P., Eck, T. F., Volten, H., Munoz, O., Veihelmann, B., van der Zande, W. J., Leon, J.-F., Sorokin, M., and Slutsker, I.: Application of spheroid models to account for aerosol particle nonsphericity in remote sensing of desert dust, $\mathrm{J}$. Geophys. Res., 111, D11208, doi:10.1029/2005JD006619, 2006.

Eck, T. F., Holben, B. N., Reid, J. S., Dubovik, O., Smirnov, A., O’Neill, N. T., Slutsker, I., and Kinne, S.: Wavelength dependence of the optical depth of biomass burning, urban and desert dust aerosols, J. Geophys. Res., 104, 31333-31349, 1999.

GCOS: Systematic observation requirements for satellite-based products for climate, GCOS -107, WMD/TD No.1338, http: //www.wmo.int/pages/prog/gcos/Publications/gcos-107.pdf, September 2006.

GTOPO-30: USGS product page: http://eros.usgs.gov/\#/Find Data/Products_and_Data_Available/gtopo30_info, 2010.

Hess, M., Koepke, P., and Schult, I.: Optical properties of aerosols and clouds: The software package OPAC, B. Am. Meteor. Soc., 79, 831-844, 1998.

Holben, B. N., Tanré, D., Smirnov, A., Eck, T. F., Slutsker, I., Abuhassan, N., Newcomb, W. W., Schafer, J. S., Chatenet, B., Lavenu, F., Kaufman, Y. J., de Castle, J. V., Setzer, A.,Markham, B., Clark, D., Froin, R., Halthore, R., Karnieli, A., O’Neill, N. T., Pietras, C., Pinker, R. T., Voss, K., and Zibordi, G.: An emerging ground-based aerosol climatology: Aerosol optical depth from 
AERONET, J. Geophys. Res., 106, 12067-12097, 2001.

Hsu, N. C., Tsay, S.-C., King, M. D., and Herman, J. R.: Aerosol Properties Over Bright-Reflecting Source Regions, IEEE, Trans. Geos. Rem. Sens., 42, 557-569, 2004.

Kaufman, Y. J., Tanré, D., Gordon, H. R., Nakajima, T., Lenoble, J., Frouin, R., Grassl, H., Herman, B. M., King, M. D., and Teillet, P. M.: Passive remote sensing of tropospheric aerosol and atmospheric correction for the aerosol effect, J. Geophys. Res., 102, 16815-16830, 1997a.

Kaufman, Y. J., Tanré, D., Remer, L. A., Vermote, E. F., Chu, A., and Holben, B. N.: Operational remote sensing of tropospheric aerosol over land from EOS moderate resolution imaging spectrometer, J. Geophys. Res., 102, 17051-17067, 1997 b.

Kokhanovsky, A. A.: Reflection and transmission of polarized light by optically thick weakly absorbing random media, J. Opt. Soc. Am., 18, 883-887, 2001.

Kokhanovsky, A. A. and de Leeuw, G.: Aerosol remote sensing over land. Springer Praxis, Chichester, 387 p., 2009.

Kokhanovsky, A. A., von Hoyningen-Huene, W., and Burrows, J. P.: Atmospheric aerosol load from space, Atmos. Res., 81, 176185, 2006

Kokhanovsky, A. A., Deuzé, J. L., Diner, D. J., Dubovik, O., Ducos, F., Emde, C., Garay, M. J., Grainger, R. G., Heckel, A., Herman, M., Katsev, I. L., Keller, J., Levy, R., North, P. R. J., Prikhach, A. S., Rozanov, V. V., Sayer, A. M., Ota, Y., Tanré, D., Thomas, G. E., and Zege, E. P.: The inter-comparison of major satellite aerosol retrieval algorithms using simulated intensity and polarization characteristics of reflected light, Atmos. Meas. Tech., 3, 909-932, doi:10.5194/amt-3-909-2010, 2010.

Maignan, F., Breòn, F.-M., and Lacaze, R.: Bidirectional reflectance of Earth targets: valuation of analytical models using a large set of spaceborne measurements with emphasis on the Hot Spot, Remote Sens. Environ., 90, 210-220, 2004.

Martiny, N., Frouin, R., and Santer R.: Radiometric calibration of SeaWiFS in the near infrared, Appl. Optics, 44(36), 7828-7844, 2005a.

Martiny, N., Santer, S., and Smolskaia, I.: Vicarious calibration of MERIS over dark waters in the near infrared, Remote Sens. Environ., 94, 475-490, 2005b.

Rozanov, V. V., Buchwitz, M., and Burrows, J. P.: SCIATRAN A new radiative transfer model for geophysical applications in the 240-2400 nm spectral region: The pseudo.spherical version, Adv. Space Res., 29, 1831-1835, 2001.

Rozanov, A. A., Rozanov, V. V., Buchwitz, M., Kokhanovsky, A. A., Burrows, J. P.: SCIATRAN 2.0 - a new radiative transfer model for geophysical applications in the $175-2400 \mathrm{~nm}$ spectral range, Adv. Space Res., 36, 1015-1019, 2005.

Schlundt, C., Kokhanovsky, A. A., von Hoyningen-Huene, W., Dinter, T., Istomina, L., and Burrows, J. P.: Synergetic cloud fraction determination for SCIAMACHY using MERIS, Atmos. Meas. Tech. Discuss., 3, 3601-3642, doi:10.5194/amtd-3-3601-2010, 2010.
Silva, A. M., Bugalho, M. L., Costa, M. J., von Hoyningen-Huene, W., Schmidt, T., Heintzenberg, J., and Henning, S.: Aerosol optical properties from columnar data during the second Aerosol Characterization Experiment an the south coast of Portugal, J. Geophys. Res., 107(D22), 4642, doi:10.1029/2002JD002196, 2002.

Treffeisen, R., Tunved, P., Ström, J., Herber, A., Bareiss, J., Helbig, A., Stone, R. S., Hoyningen-Huene, W., Krejci, R., Stohl, A., and Neuber, R.: Arctic smoke - aerosol characteristics during a record smoke event in the European Arctic and its radiative impact, Atmos. Chem. Phys., 7, 3035-3053, doi:10.5194/acp-73035-2007, 2007.

von Hoyningen-Huene, W. and Posse, P.: Non-sphericity of Aerosol Particles and Their Contribution to Radiative Forcing, J. Quant. Spectr. Rad. Trans., 57, 651-668, 1997.

von Hoyningen-Huene, W., Schmidt, T., Schienbein, S., Chan, A. K., and Lim, J. T.: Climate relevant aerosol parameters of SouthEast Asian forest fire haze, Atmos. Environ., 33, 3183-3190, 1999a.

von Hoyningen-Huene, W., Wenzel, K., and Schienbein, S.: Radiative Properties of Desert Dust and its Effect on Radiative Balance, J. Aeros. Sci., 30, 489-502, 1999b.

von Hoyningen-Huene, W., Freitag, M., and Burrows, J. B.: Retrieval of aerosol optical thickness over land surfaces from top-of-atmosphere radiance, J. Geophys. Res., 108(D9), 4260, doi:10.1029/2001JD002018, 2003.

von Hoyningen-Huene, W. A., Kokhanovsky, A., Burrows, J. P., Bruniquel-Pinel, V., and Regner, P.: Simultaneous Determination of Aerosol- and Surface Characteristics from Top-ofAtmosphere Reflectance using MERIS on board of ENVISAT, J. Adv. Space Res., 37, 2172-2177, 2006.

von Hoyningen-Huene, W., Kokhanovsky, A. A., and Burrows, J. P.: Retrieval of Particulate Matter from MERIS Observations, in: Advanced Environmental Monitoring, edited by: Kim, J. Y. and Platt, U., Springer, 190-202, 2008.

von Hoyningen-Huene, W., Dinter, T., Kokhanovsky, A. A., Burrows, J. P., Wendisch, M., Bierwirth, E., Müller, D., and Diouri, M.: Measurements of desert dust optical characteristics at Porte au Sahara during SAMUM, Tellus, 61B, 206-215, 2009.

Yoon, J. M., von Hoyningen-Huene, W., Vountas, M., and Burrows, J. P.: Analysis of long-term trend of aerosol optical thickness using Bremen AErosol Retrieval algorithm with SeaWiFS data over regions of interest, Atmos. Chem. Phys. Discuss., in preparation, 2011. 